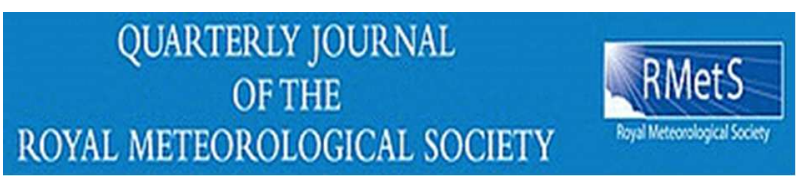

\title{
Impact of targeted observations on HIRLAM forecasts during HyMeX-SOP1
}

\begin{tabular}{|r|l|}
\hline Journal: & QJRMS \\
\hline Manuscript ID: & Draft \\
\hline Wiley - Manuscript type: & HyMeX Special Issue \\
\hline Date Submitted by the Author: & n/a \\
\hline Complete List of Authors: & $\begin{array}{l}\text { Campins, Joan; AEMET, Delegación AEMET en Illes Balears } \\
\text { Navascués, Beatriz; AEMET, }\end{array}$ \\
\hline Keywords: & $\begin{array}{l}\text { Targeted observations, HyMeX, HIRLAM, Observing System Experiment, } \\
\text { High-impact weather events }\end{array}$ \\
\hline \multicolumn{2}{|l}{} \\
\hline
\end{tabular}




\title{
Impact of targeted observations on HIRLAM forecasts during HyMeX-SOP1
}

\author{
J. Campins ${ }^{1}$ and B. Navascués ${ }^{2}$ \\ ${ }^{1}$ Agencia Estatal de Meteorología, Palma, Spain \\ ${ }^{2}$ Agencia Estatal de Meteorología, Madrid, Spain \\ Running head: Impact of targeted observations on HIRLAM forecasts during HyMeX-SOP1 \\ Keywords: Targeted observations, HyMeX, HIRLAM, Observing System Experiments, High- \\ impact weather events
}

\begin{abstract}
We explore an adaptive observing system with terrestrial and space-based components, with the aim to improve the Numerical Weather Prediction skill in the Mediterranean. Four Observing System Experiments based on the HIRLAM system have been conducted to test the influence of targeted observations on short-term forecasts of high-impact weather events over the first Special Observation Period of HyMeX international project. We assimilate as targeted observations extra radiosoundings and enhanced Advanced TIROS Operational Vertical Sounders (ATOVS) satellite observations. The two different types of targeted observations have been added to the baseline first separately and then jointly. In general, targeted observations have a positive but small impact on the short-term forecasts, noticeably at $700-500 \mathrm{hPa}$ in all parameters and precipitation. Targeted radiosoundings produce a clear overall improvement of HIRLAM forecasts. Data targeting based only on satellite observations has a generally positive impact on precipitation, and in short-term forecasts of the rest of parameters. The assimilation of both types of extra observations produces the highest and most statistically significant improvements. The magnitude of the impact on the forecasts depends on the weather regime that determines the location of sensitive areas. According to the diagnostics obtained from the data assimilation cycle, the targeted observations had a still larger positive influence on the subsequent analyses. Extra radiosoundings and additional satellite radiances clearly improve the first guess quality over land and sea sensitive areas respectively.
\end{abstract}




\section{Introduction}

The Hydrological Cycle in the Mediterranean Experiment (HyMeX) is a 10-yr international project devoted to study the water cycle in the Mediterranean with special interest on high-impact weather events (Dobrinski et al., 2014). An essential component of this program is to develop an observation strategy by means of field campaigns to improve the knowledge of key processes of the water cycle and related high-impact weather events. The first field campaign (so-called SOP1 for Special Observation Period) was devoted to heavy precipitations and flash-floods in the Western Mediterranean, and spanned from 5 September to 6 November 2012. Research ground instruments, in addition to operational meteorological and hydrological networks were developed in the SOP1 domain. Some of these means were kept constantly active through the whole SOP1, but others were activated on demand, during or before predicted potential heavy precipitation events, the so-called Intensive Observation Periods (IOPs). Extra-ordinary observations can be used to improve the knowledge of the state of the atmosphere prior or during the occurrence of intense events, but also to investigate the potential improvement of Numerical Weather Prediction (NWP) models of those events (i.e. as targeted observations).

The targeted component for SOP1 was possible thanks to the agreement between HyMeX and EUCOS, the Program for the Composite Observing System of the European Consortium of National Meteorological Services, EUMETNET. A similar collaboration took place in former field campaigns as DTS-PREVIEW-2008 and DTS-MEDEX-2009 (Campins et al., 2013). The implementation of an adaptive observation component for SOP1 lies on the Data Targeting System (DTS), a web-based tool which manages the entire data targeting process. The DTS development was carried out by the European Centre for Medium-Range Weather Forecasts (ECMWF), in partnership with the UK Met Office. Since 2008, DTS has supported some field campaigns, as THORPEX-IPY (Irvine et al., 2011), T-PARC (Kim et al., 2011), PREVIEW (Prates et al., 2009) 
and MEDEX (Jansà et al., 2011). The targeting process involves three main steps. First, a potential high-impact weather event is identified. Next, the regions where the inclusion of additional observations may improve the forecast of this event are calculated. This is the Sensitive Area Prediction (SAP) step. And finally, the additional observations to be deployed as targeted observations are selected. For HyMeX-SOP1, and based on DTS, a similar approach than the one used in previous field campaigns was used, but with a few small changes. The main modification was the setup of an automatic computation of SAPs for a fixed area (the North-Western Mediterranean) and for pre-determinated lead-times. The time lag between the targeting and the verification times ranged between $18 \mathrm{~h}$ and $30 \mathrm{~h}$, as the focus was on the short-range forecasts. The aim of these changes was to advance as much as possible the evaluation of sensitivity information. However, moveable smaller areas for selected lead-times were allowed if necessary. An exhaustive description of the DTS is given in Prates et al., 2009, and the adaptation for SOP1 in Ducrocq et al., $2014 a$.

Over the past years several research experiments have included a targeting component in their field experiments (Langland, 2005; Majumdar et al., 2011). Recently, Campins et al. (2013) have explored the usage of targeted observations deployed during DTS-PREVIEW-2008 and DTSMEDEX-2009 to improve the forecast of high-impact weather events in the Mediterranean. They have carried out some Observing System Experiments (OSEs) based on the assimilation of targeted radiosondes, and found an overall positive impact using the HIRLAM-4DVar Numerical Weather Prediction (NWP) system. Furthermore, the forecast skill was increased when enhanced Advanced TIROS Operational Vertical Sounders (ATOVS) satellite data over oceanic sensitive regions were also assimilated. These results were obtained in two short periods (one week each), with a small number of events (12 per period). 
In this work we further explore the potential of adaptive observations based on the terrestrial and space-based observing systems. We introduce a new OSE to assess the impact of the assimilation of an enhanced satellite observations density, as the unique targeted data. Then, we analyse the separate and joint contribution of radiosoundings and raw radiances. The influence of targeted observations on short-range forecasts of high-impact weather events is studied during the full HyMeX-SOP1. This is a longer period (two months) that included a larger number of cases (52) over a fixed verification area. It is intended to obtain more robust results from the statistical point of view. We assess the impact of the different OSEs by carrying out an objective verification of the corresponding forecasts against analysis, radiosonde data, surface meteorological observations and rain gauge data from a high resolution stations network.

The impact of data targeting on forecasts depends on the distribution and types of regular and targeted observations, the quality of the background, and the ability of the data assimilation procedure to combine information from the background and observations (Langland, 2005). As part of the OSEs evaluation, we also examine some aspects about the performance of the data assimilation cycle. In particular, we look into the background departures of the different observation types to check the influence of targeted data in the first guess in the sensitive areas.

The results obtained by Campins et al. (2013) have shown a distinct impact of targeted data during DTS-PREVIEW-2008 and DTS-MEDEX-2009. It was argued that it was due to the distinct weather regimes that dominate over each period and the existing composite observing system. In this study the impact of targeted observations is investigated grouping the events in the different weather regimes occurred along the SOP1. The results obtained are analysed taking into account the location of the sensitive areas and the nearby observations assimilated.

The paper is structured as follows. Section 2 describes the set-up of the targeting experiments and 
the methodologies used to assess the impact on forecasts. Next, the results over the whole SOP1, and for each individual period are given in Sections 3 and 4, respectively. The last section (Section 5) outlines the main conclusions and some final remarks.

\section{Experimental set-up and verification methodology}

The set-up and verification methods employed in these observing system experiments follow closely those performed previously by Campins et al. (2013) to test the influence of radiosondes deployed during DTS-PREVIEW-2008 and DTS-MEDEX-2009 campaigns on the forecasts of high-impact weather in the Mediterranean.

\subsection{HIRLAM data assimilation and forecasting system}

The OSEs presented here have been carried out with the HIRLAM NWP system (Undén et al., 2002), on a rotated grid at $0.15^{\circ}$ horizontal resolution with 60 vertical levels. The parametrization for clouds and condensation processes is based on Kain-Fritsch for convection (Kain, 2004) and Rasch-Kristjansson for large-scale microphysics (Zhang et al., 2003). In these experiments we have used the incremental HIRLAM 4-D variational data assimilation (DA) system, 4DVar (Gustafsson et al., 2012), as upper-air analysis with a $6 \mathrm{~h}$ time window. Conventional and satellite radiances are assimilated as described in Lindskog et al. (2001), and Schyberg et al. (2003) respectively. Physical processes are represented in the tangent linear and adjoint models. Operational forecast fields from the Integrated Forecast System (IFS, cycle Cy38r1, http://old.ecmwf.int/research/ifsdocs/CY38r1/) of the ECMWF global model, started from T-6 analysis, are used as boundary conditions. During the HyMeX-SOP1 most of the extra radiosoundings were disseminated through the Global Telecommunications System (GTS) and were assimilated by the IFS-ECMWF global model. The HIRLAM model domain covers most of the North Atlantic Ocean, Europe and North Africa and its 
boundaries are far away from the different targeting areas where the additional observations were deployed. So, we expect a minor impact of targeted observations through the boundaries. Nevertheless, the results obtained with these experiments will become much definite if similar OSEs were carried out with the global model to be used as boundary conditions.

\subsection{Experiment description}

A first goal of this study is to assess the impact of the DTS radiosoundings deployed on short-range forecasts of HyMeX-SOP1 cases. In addition, we also evaluate the impact of the assimilation of a larger volume of satellite observations as part of an adaptive composite observations system. During HyMeX-SOP1 sensitive areas were incompletely surveyed, because they covered wide areas in the North Atlantic to the west of the Iberian Peninsula where no radiosonde stations were available. Previous results have indeed demonstrated the benefit of the assimilation of larger volumes of satellite observations in sensitive regions by means of changes in some data assimilation procedures, in particular the data thinning (e.g. Bauer et al., 2011; Campins et al., 2013). In order to test the impact of the different types of targeted observations we have conducted the following Observing System Experiments (Table 1):

- We have defined a baseline experiment, CTRL, that assimilates all types of surface and upper-air conventional data, plus ATOVS raw radiances from the Advanced Microwave Sounding Unit-A and Unit-B (AMSU-A and AMSU-B), and the Microwave Humidity Sounder (MHS). This is the "normal" situation experiment. In CTRL experiment extra radiosoundings are blacklisted and then screened out of the minimization. ATOVS data are thinned with the normal HIRLAM set-up. 
- DTS RS experiment tests the impact of DTS radiosoundings, and they are added to the baseline.

- ATOVS2_B experiment has been conducted to test the potential of satellite observations as the only source of targeted data. This is achieved through changes in the data assimilation procedures. In ATOVS2_B there is an addition of satellite observations to the baseline, by assimilating a double density of ATOVS data in the sensitive sea areas.

- ATOVS2 experiment tries to test the impact of a more complete sampling of target regions. As in Campins et al. (2013), it allows for an enhanced sampling of ATOVS data located in the sensitive regions over the sea areas to complement the DTS extra radiosoundings. In this case, DTS radiosoundings and double density of ATOVS data in sensitive areas (only at the analysis times corresponding to the targeting times) are added to the baseline.

\title{
2.3. Distribution of upper-air observations in Control and Data Targeting Experiments
}

The upper-air observations that feed the HIRLAM data assimilation system come from three information sources: aircraft (AMDAR meteorological reports), radiosondes and satellite sounders (ATOVS). Next, we briefly review the availability and spatial distribution of these observation types at target times during the HyMeX-SOP1 campaign.

\begin{abstract}
AMDAR data
AMDAR observations include upper-level observations (from en-route aircraft) as well as vertical profiles (on ascent or descent phases) of air temperature and wind. The mean number of AMDAR data in boxes of $5^{\circ} \times 5^{\circ}$ lat/lon assimilated by CTRL experiment at the target times (06 and 18 UTC) is displayed for upper-level data (below $400 \mathrm{hPa}$, Figure 1a) and vertical profiles (above $400 \mathrm{hPa}$, Figure 1b). The same set of AMDAR data was assimilated by all the HIRLAM experiments conducted in this study. Figures $1 \mathrm{a}$ and $1 \mathrm{~b}$ show that the spatial distribution of this data source was
\end{abstract}


far from uniform during HyMeX-SOP1. In some land regions, as Northern Africa, AMDAR data was the only available information on the vertical structure of the atmosphere that could be assimilated. Besides, AMDAR data provide valuable upper-level observations in some oceanic regions (e.g. the latitude band $45^{\circ} \mathrm{N}-60^{\circ} \mathrm{N}$ over the North Atlantic), although sparse data areas dominate to the south of $45^{\circ} \mathrm{N}$. The spatial pattern shown in Figures 1a and $1 \mathrm{~b}$ was almost constant along the HyMeX-SOP1.

\section{Radiosondes}

Most of the operational radiosonde stations routinely launch upper air soundings at 00 and 12 UTC, but some of them also operate at 06 and 18 UTC (targeting times). This is the case for some stations located over Central Europe and British Islands and some ships under the EUMETNET Automatic Ship Aerological Program (ASAP) operating in the Atlantic. All these radiosondes are assimilated by CTRL and the three Data Targeting Experiments and are displayed in black in Figure 1d.

On the contrary, the DTS radiosoudings (so-called DTS RS hereafter) were launched on demand at 06 and 18 UTC from several operational stations operated by some European National Meteorological Services (mainly in Spain, France and Italy) through EUCOS DTS requests. These observations were assimilated by DTS_RS and ATOVS2 experiments. The location and number for the HyMeX-SOP1 are displayed in red in Figure 1d. They covered nicely the Iberian Peninsula and the European border of the Western Mediterranean, but there were not additional upper air soundings deployed in the African side.

\section{ATOVS data}

These HIRLAM experiments assimilated raw radiances in sea areas from AMSU-A (NOAA18, NOAA19, and MetOp satellites), AMSU-B (NOAA16 satellite) and MHS (NOAA18, NOAA19, 
and MetOp satellites) instruments. AMSU-A provides information on the temperature atmospheric profile, whereas AMSU-B and MHS help to determine the moisture initial state.

The default data thinning of these data in the HIRLAM observation screening step allows a minimum distance between them of $0.9^{\circ}$ lat/lon. CTRL and DTS_RS adopted this configuration. In these experiments the ATOVS data density is uniform in sea areas, with small differences from case to case. ATOVS2 and ATOVS2_B experiments are designed to test the impact of ATOVS as targeted data by means of a variable satellite data density, being larger in the sensitive areas. So, in these regions the minimum thinning distance is reduced to $0.45^{\circ}$ lat/lon, and the nominal thinning distance $\left(0.9^{\circ}\right.$ lat/lon $)$ is kept in the rest of sea areas. This simple procedure is applied to all the channels used (10 in case of AMSU-A, 5 in case of AMSU-B/MHS) whatever the data density of the rest of observation types around each satellite observation location. Figure 1c shows the increase of ATOVS data assimilated due to the different thinning distance employed (relative ratio of data accepted by the data assimilation -in \%- between ATOVS2 and CTRL). The highest increase in ATOVS data assimilated corresponds to lat/lon boxes that were most often identified by SAPs as sensitive areas during this HyMeX-SOP1. It can be observed that they are North Atlantic and Mediterranean regions surrounding the Iberian Peninsula.

\subsection{Assessment methodology}

\section{Performance of the data assimilation cycle}

To evaluate the influence of targeted observations, we first examine some aspects of the performance of the data assimilation cycle for each experiment. A better background estimate is an indication of improved past analyses and leads naturally to smaller innovations in the present analysis and to a more accurate initial state. 
Instead of sporadic, targeting times were very close to each other during the distinct high-impact weather events within HyMeX-SOP1. This fact, and the relatively high number of extra observations assimilated in the OSEs presented in this work, produced an effect in the first guess for the analyses run at the targeting times. We make use of the a posteriori information of the analysis to look into the observation minus first guess values, or background departures, mainly for the two types of targeted data employed: radiosonde and ATOVS brightness temperatures. It allows to check the quality of the first guess at the targeting times in the different sensitive areas that were mostly sampled by radiosondes (land regions) and by enhanced satellite observations (sea areas). We further distinguish two broad North Atlantic sensitive regions, to the north and to the south of $45^{\circ} \mathrm{N}$. The reason for it is the different observations density existing routinely between them, with a changing relevance of the additional data that are assimilated.

\section{Objective verification against analyses and observations}

In a second and third step, the assessment of these experiments is based on the comparison of the model forecasts started at the different targeting times of the HyMeX-SOP1, against NWP analyses and surface and upper air observations within the Verification Area (VA), the region within the box displayed in Figure 1.

Verification results may depend strongly on the analysis selected. To avoid this shortcoming an independent analysis, the operational IFS-ECMWF (Cy38r1), has been used as verifying analysis. The analyses, which initial resolution is T1279 $(\sim 16 \mathrm{~km})$, have been interpolated to the HIRLAM resolution.

Classical scoring rules have been used to assess the large scale model performance of the different experiments. In particular, root mean square error (RMSE; Wilks, 2011) of forecast fields with respect to analysis fields for all the grid points included in the verification area (VA) at the 
verification time (VT) is used. Skill scores are often used as a relative measure of performance with respect to a reference forecast (Wilks, 2011). Particularly, for a certain Data Targeting Experiment

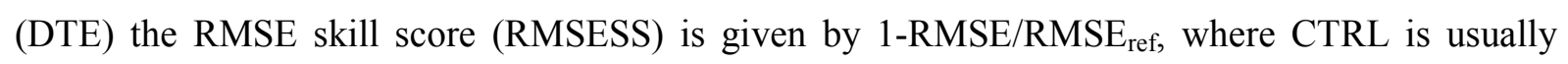
used as reference (to evaluate the impact of ATOVS2_B and ATOVS2 the DTS_RS can be also used as reference). For convenience we use the percentage of reduction/increasing just multiplying by 100 and we call it relative RMSE (REL_RMSE). Its interpretation is straightforward: when REL_RMSE is positive/negative, the DTE (Data Targeting Experiment) forecast error is lower/higher than CTRL and therefore there is an improvement/deterioration. REL_RMSE has been calculated for Geopotential height (Z), Temperature (T), Wind speed (SPD) and Relative Humidity $(\mathrm{RH})$ at 5 standard pressure levels.

To determine whether differences in results between paired experiments are statistically significant we performed a Student's t test for the mean difference in two different RMS forecast error (in fact the REL_RMSE). The null hypothesis $\left(\mathrm{H}_{0}\right)$ is that the population mean of individual relative RMSE of paired observations is zero. If the null hypothesis is rejected, there must be a statistically significant difference between the two experiments. A two-sided confidence interval of $90 \%$ was used to define the significance interval.

We have also carried out an objective verification of upper air variables and surface parameters, with emphasis on precipitation.

Vertical profiles of RMSE for geopotential height, temperature, wind speed and relative humidity of the HIRLAM forecasts started from the 52 targeting time analyses have been obtained using the available TEMP observations in the VA (15 radiosonde stations). 
Mean sea level pressure and $12 \mathrm{~h}$-accumulated precipitation data, contained in all available SYNOP reports from land meteorological stations located in the fixed verification region, have been used to verify only those forecasts started from the different targeting time analyses. REL_RMSE has been obtained for each experiment. Equitable threat score (ETS) from corresponding contingency tables for different thresholds of $12 \mathrm{~h}$-accumulated precipitation has also been calculated.

During HyMeX-SOP1 a special effort has been carried out to collect rain gauge observations from dense networks over France, Italy and Spain. For the present study, daily precipitation data received in near-real time during SOP1 (see for instance Fig. 6 from Ducrocq et al., 2014b) have been increased with $24 \mathrm{~h}$ accumulated rain gauge data from the Spanish climate station network. The total number of stations within the verification area amounts to almost 8000 . These data has been used to verify daily precipitation forecasts (from 06 UTC to 06 UTC) of the different experiments. ETS from corresponding contingency tables for different threshold of $24 \mathrm{~h}$ accumulated precipitation has been calculated. The scores for $24 \mathrm{~h}$-accumulated precipitation presented in this paper correspond to the verification of those forecasts started from the targeting time analyses against these high resolution rain gauge data.

\section{Overall results for the HyMeX-SOP1}

\subsection{Performance of the data assimilation cycle}

As it has been mentioned, the different distribution of regular and targeted observations in each experiment suggests to analyse the departures between observations and the model background for the all the targeting time analyses in separate regions. 
We first examine the fit of the first guess to the observations along the vertical, by means of the root mean square of background departures of radiosonde data, for the region around the Iberian Peninsula. We have also calculated these vertical profiles for two North Atlantic regions: southwards of $45^{\circ} \mathrm{N}$ (i.e. from $25^{\circ} \mathrm{N}$ to $45^{\circ} \mathrm{N}$ and from $30^{\circ} \mathrm{W}$ to $10^{\circ} \mathrm{W}$ ) and northwards of $45^{\circ} \mathrm{N}$ (i.e. from $45^{\circ} \mathrm{N}$ to $60^{\circ} \mathrm{N}$ and from $30^{\circ} \mathrm{W}$ to $10^{\circ} \mathrm{W}$ ). Sensitive regions located in these two last regions were poorly sampled by a few targeted radiosondes, but in two of the experiments the density of ATOVS data was doubled there. In these regions ASAP reports are also available.

In the region over or close to the Iberian Peninsula (from $35^{\circ} \mathrm{N}$ to $45^{\circ} \mathrm{N}$; and from $10^{\circ} \mathrm{W}$ to $5^{\circ} \mathrm{E}$ ), where most of the targeted radiosondes were deployed, background departures (Figure 2) show a clear improvement of the data assimilation cycle due to the targeted radiosondes that have been assimilated at 06 and 18 UTC (DTS_RS and ATOVS2 versus CTRL and ATOVS2_B). The additional satellite data have a marginal impact, only noticed on the wind first guess (Figures 2c and 2d) and seems to be slightly negative. It is worthwhile to mention that in this region, only at 00 at 12 UTC there are radiosoundings that can be assimilated routinely.

In the North Atlantic region southwards of $45^{\circ} \mathrm{N}$ (not shown), background departures for the available radiosonde data indicate that the effect of the assimilation of targeted radiosonde observations is much smaller and extra satellite radiances produce an overall improvement in the data assimilation cycle over oceanic sparse data areas for all variables. The benefit on the first guess is larger in wind than in temperature and specific humidity. For these two variables the improvement is more noticeable at $850 \mathrm{hPa}$. Humidity is systematically improved in the vertical by ATOVS2 experiment. If the root mean square of background departures is calculated using only those ASAPS that were assimilated by all the experiments, the first guess of the experiment ATOVS2_B is comparable or better than that of ATOVS2, indicating that extra satellite data assimilated are the main responsible for the improvement of the assimilation cycle in these oceanic 
areas.

Results for the North Atlantic region northwards of $45^{\circ} \mathrm{N}$ present lower background departures than their counterparts in the region southwards of $45^{\circ} \mathrm{N}$ (not shown). They are particularly small for the wind components, temperature (except at around $850 \mathrm{hPa}$ ) and specific humidity (in this case it should be taken into account a lower content at higher latitudes). Differences between experiments are also rather small.

We have also looked into the innovations of the different AMSU-A and AMSU-B/MHS channels assimilated in the same oceanic regions. These data present an advantage with respect to other observing sources: they provide uniform observation coverage in these sea areas that were very often predicted as sensitive regions for the high-impact weather events studied.

Figure 3 displays the difference between the root mean square of background departures for AMSUA channels of each OSE and that of CTRL (positive/negative values indicate a better/worse first guess than CTRL according to the bias corrected brightness temperature observations). Although observation minus first guess values for channels 1-10 (AMSU-A) and 1-5 (AMSU-B/MHS) are presented to the minimization process, the observation errors assigned to those channels peaking at or close to the surface are very high and then in practice these observations have not weight in the analysis. Nevertheless, the first noticeable feature that can be mentioned is that background departures for brightness temperatures in these channels for both AMSU-A (see Figure 3) and AMSU-B/MHS (not shown) indicate a systematic improvement of the lowest troposphere first guess in the two oceanic areas due to the enhanced satellite data assimilated. On the other hand, AMSU-A innovations (Figure 3) seem to be more sensitive to the assimilation of extra radiances than those of AMSU-B/MHS (not shown). Figure 3b also shows that all types of targeted data improve the background in the oceanic area to the south of $45^{\circ} \mathrm{N}$, ATOVS2_B, the experiment that 
only assimilated extra radiances the most, and DTS_RS, the one that only assimilated DTS radiosonde the less. Figure 3a suggests that the impact of targeted data in the oceanic areas to the north of $45^{\circ} \mathrm{N}$ is much smaller, but clearly positive for the experiment that only assimilated extra satellite observations as targeted data.

Innovations of other data types (aircraft, ships and buoys) in these oceanic areas present smaller differences between the experiments (not shown), but they are sparse observations and their distribution is much irregular. However, in all the regions studied and according to the background departures of radiosonde data and satellite radiances, whenever there is a significant impact in the data assimilation cycle, the first guess is improved with respect to CTRL by at least a $10 \%$.

Summarising, these diagnostics of the data assimilation cycle performance seem to indicate that, in these OSEs, the first guess was influenced by the data targeting method employed. The magnitude of the impact found depends on the background quality itself and on the observing system distribution. In particular, there is a dominant role of radiosonde data over the Iberian Peninsula and surroundings, and a significant impact of the additional satellite data assimilated over the oceanic sensitive areas, mainly those that are sparse data regions.

\subsection{Verification against IFS analysis}

Table 2 shows the overall improvement/deterioration obtained by each DTE with respect to CTRL during the whole HyMeX-SOP1, by means of the calculated REL_RMSE. It can be observed that, in general,even though improvements clearly dominate over deteriorations, the overall impact obtained is small (smaller than $5 \%$ ) and only few values are statistically significant. No pattern can be discerned, values largely depends on the parameter, vertical level and experiment. Nevertheless, 
for some parameters,individual forecasts have shown an impact (either positive or negative) larger than $20 \%$ (not shown).

Geopotential height is improved at mid-upper levels by DTS_RS and ATOVS2_B. In both experiments one single observation type is added to the baseline as targeted data. All the experiments improve CTRL at $700 \mathrm{hPa}$. The only statistically significant difference with respect to CTRL in geopotential height is found at $700 \mathrm{hPa}$ for ATOVS2_B, being the maximum improvement among all levels/experiments.

Temperature is the parameter that presents a smaller overall sensitivity to data targeting in this SOP1.

All experiments seem to slightly deteriorate wind speed at the lowest levels due to the assimilation of extra observations. However, all DTEs improve CTRL at $500 \mathrm{hPa}$, and these differences are significant for all the experiments that assimilate extra wind observations (DTS_RS and ATOVS2).

Relative humidity is the variable with a largest number of statistically significant differences with respect to CTRL. All experiments perform slightly worse than CTRL at 850 and $925 \mathrm{hPa}$, but the improvements reached at 700 and $500 \mathrm{hPa}$ by DTS_RS and ATOVS2 are higher. At 700 and 500 hPa all DTEs are able to improve CTRL, being the best ATOVS2, followed by DTS_RS.

In general, it seems that all experiments slightly improve CTRL for geopotential height, wind speed, and relative humidity at $700-500 \mathrm{hPa}$, and perform worse than CTRL, but to a lesser extent, in the case of wind and humidity at the lowest levels. DTS_RS shows the highest overall impact, and it is mostly positive. Taking into account only those REL_RMSEs that are statistically significant, ATOVS2 presents the highest improvement. 


\subsection{Verification against TEMP and surface observations}

Vertical profiles of RMSE for CTRL, DTS_RS, ATOVS2 and ATOVS2_B for geopotential height, temperature, wind speed, and relative humidity, have been calculated using observations contained in TEMP reports, and are displayed in Figure 4. The overall impact observed is rather (but not fully) consistent with the results obtained in the verification against analysis. However, the impact of the extra observations is slightly larger and it is mostly positive or neutral (depending on the parameter, vertical level and experiment).

The three DTEs seem to improve clearly geopotential height at mid-upper levels. When DTEs forecasts are verified against temperature observations, there is a positive impact of the additional data at low and mid levels (only at $500 \mathrm{hPa}$ in the case of ATOVS2, the experiment assimilating a larger number of extra data). The three experiments also show an improvement of wind speed at $500 \mathrm{hPa}$, and a large impact at $300 \mathrm{hPa}$ that does not appear in the analysis verification (negative in the case of ATOVS2 and ATOVS2_B, the experiments assimilating additional ATOVS data). The impact observed in relative humidity is either positive or neutral at all levels. ATOVS2 improves consistently the vertical profile of relative humidity. The other two experiments show a clear improvement in relative humidity produced by the targeted data at $500 \mathrm{hPa}$, and in the case of ATOVS2_B, the experiments assimilating additional ATOVS data, also at $700 \mathrm{hPa}$.

In general, at $500 \mathrm{hPa}$ the three DTEs improve CTRL for all parameters. Geopotential height and wind speed also show an impact at $300 \mathrm{hPa}$ and temperature and relative humidity below $500 \mathrm{hPa}$.

Table 3 shows the REL_RMSE of mean sea level pressure (MSLP) calculated for DTS_RS, ATOVS2 and ATOVS2_B experiments for the three forecast ranges valid at the verification times: 
$\mathrm{H}+18, \mathrm{H}+24$ and $\mathrm{H}+30$. A small improvement or deterioration with respect to CTRL can be mentioned for $\mathrm{H}+18$ and $\mathrm{H}+24$, but for $\mathrm{H}+30$ the mean relative error is reduced for all the three experiments, especially for ATOVS2_B and DTS_RS.

Table 4 displays the REL_RMSE of the accumulated precipitation (in $\mathrm{mm} / 12 \mathrm{~h}$ ) calculated for DTS_RS, ATOVS2 and ATOVS2_B. Both ATOVS2_B and ATOVS2 (less) improve the rainfall forecasted by CTRL for the three lead-times. However, DTS_RS only does it at short-range. It must be taken into account that the number of $12 \mathrm{~h}$ accumulated precipitation observations is very low for $\mathrm{H}+18$ and $\mathrm{H}+30$.

Figure 5a shows the ETS for different thresholds of $12 \mathrm{~h}$-accumulated precipitation for CTRL, and DTS_RS, ATOVS2 and ATOVS2_B experiments. It can be observed that ATOVS2 obtains the best scores for all thresholds. For light to moderate precipitation (1-10 mm/12 h thresholds) DTS_RS and ATOVS2_B experiments are also able to improve CTRL. Scores for intense precipitation $(>30$ $\mathrm{mm} / 12 \mathrm{~h}$ ) results are not significant as only two cases were observed.

For $24 \mathrm{~h}$ accumulated precipitation (Figure $5 \mathrm{~b}$ ), it can be observed that for light to moderate precipitation (3-10 $\mathrm{mm} / 24 \mathrm{~h}$ thresholds) the three DTEs improve CTRL, but for intense precipitation $(30 \mathrm{~mm} / 24 \mathrm{~h}$ threshold) only those experiments assimilating DTS extra radiosondings (DTS_RS and ATOVS2) are also able to improve CTRL. Scores for heavy precipitation (> 60 $\mathrm{mm} / 24 \mathrm{~h}$ ) results are less significant as a few cases were observed.

\section{Results for individual periods}

As in Campins et al. (2013) for DTS-PREVIEW-2008 and DTS-MEDEX-2009, we have analysed the influence of targeted observations over individual periods of the whole two-month data 
targeting field campaign. During HyMeX-SOP1, different weather regimes alternate (Cassou et al., 2004 and Ducrocq et al., 2014b). From 5 to 22 September the Atlantic ridge dominated, allowing some heavy precipitation events (HPEs) over Northern and Central Italy. Afterwards, the weather regime shifted to a negative phase of the North Atlantic Oscillation (NAO-), providing a favourable large-scale environment for HPEs over the whole SOP1 domain from 23 to 30 September. From 1 to 15 October the positive phase of the North Atlantic Oscillation $(\mathrm{NAO}+)$ followed, with few HPEs over the northern regions of the SOP1 domain. After that period of $\mathrm{NAO}+$, weather patterns became favourable again to HPEs along the SOP1 domain with a Blocking (16-26 October) and NAO- (27 October-6 November) patterns.

The two-month period of SOP1 embraced several high-impact weather events in the Western Mediterranean. Most of these events were included into one of the eighteen IOPs (two for orographic precipitacion events and sixteen for heavy precipitation events). A general overview of all the IOPs and some highlights for some specific ones (IOP 6, 8, and 16a) can be found in Ducrocq et al., 2014b. All heavy rain events that occurred in Spain during SOP1 are described in Jansà et al., 2014. In Ferretti et al., 2014, selected significant events (IOPs 2, 13 and 19) for Italian regions are analysed. From another point of view, in Hally et al., 2014, IOPs 6 and 7a that occurred over south-eastern France, are described.

The impact of targeted observations is examined for each one of these large-scale atmospheric patterns. We first analyse the average spatial pattern of the sensitive areas that are displayed in Figure 6. Next, we briefly review the baseline observing system distribution and the additional observations assimilated by the different experiments (Figures 7 and 8). Finally, we focus on those parameters which significantly improved any Data Targeting Experiment, that is, relative humidity at 700 and at $500 \mathrm{hPa}$, geopotential height at $700 \mathrm{hPa}$ and wind speed at $500 \mathrm{hPa}$. The mean relative RMS errors (in \%) for these parameters (calculated by the verification against IFS-ECMWF 
analysis) are presented for each weather regime period in Table 5. Equitable threat score for accumulated precipitation (in 24 hours) for each period is displayed in Figure 9.

\subsection{From 5 to 22 September: Atlantic ridge}

During this period, DTS radiosondes were deployed in 9 cases, covering one orographic precipitation event (IOP 1) and two heavy precipitation events (IOPs 2 and 4). Sensitive regions located in North Atlantic, upstream of the Atlantic ridge and to a lesser extent, to the west and south-west of the Iberian Peninsula, and over the Western Mediterranean (Figure 6a), in a NW-SE pattern. Experiments ATOVS2 and ATOVS2_B assimilated additional ATOVS data more often in the oceanic region to the west of the British Isles (not shown). However, that region was relatively well sampled by aircraft data. The oceanic sensitive areas were less frequent to the south of $45^{\circ} \mathrm{N}$, but in these cases doubling the ATOVS data density there, produced an increase of the number of assimilated observations in a sparse data region (even though some ASAPs were deployed). In the Western Mediterranean the number of observations assimilated increased due to the extra EUCOSDTS radiosondes.

Table 5 shows that ATOVS2 and DTS_RS DTEs improved CTRL in the most sensitive parameters identified for the whole SOP1 period. All these DTEs assimilated additional radiosoundings with respect to the baseline. The positive impact reaches in some cases values close to a $10 \%$ and it is significant for relative humidity at $700 \mathrm{hPa}$ and wind speed at $500 \mathrm{hPa}$. However ATOVS2_B, the experiment that only used enhanced satellite observations as targeted data, shows a small deterioration with respect to CTRL in these parameters.

Figure 9a shows equitable threat scores for $24 \mathrm{~h}$ accumulated precipitation in this period. It can be seen that for light to moderate precipitation (3-10 $\mathrm{mm} / 24 \mathrm{~h}$ thresholds), scores are rather similar for 
all the experiments, ATOVS2_B slightly worse than CTRL. However, for intense precipitation (30 $\mathrm{mm} / 24 \mathrm{~h}$ threshold) all the DTEs improve the forecasted rainfall with respect to CTRL.

Summarising, in this period the influence of targeted radiosonde observations was positive and the maximum benefit is found when not only DTS radiosondes but also additional satellite data in sensitive regions are assimilated. However, the single usage of ATOVS observations as targeted data in this period produces a small negative impact.

\subsection{From 23 to 30 September: NAO-}

During this short period data targeting was deployed in 12 cases, including some intense heavy precipitation events (IOPs 6, 7ab and 8). Sensitive regions spread along the upper-level trough centred to the south-west of the Iberian Peninsula, with maximum located on the right side of the through, in a SW-NE pattern (see Figure 6b). Figure 7 shows that experiments ATOVS2 and ATOVS2_B assimilated more often additional ATOVS data to the south of $45^{\circ} \mathrm{N}$, to the west and south-west of the Iberian Peninsula and in the Mediterranean between the Catalonian coast and Corsica. The North Atlantic regions are sparse data areas where enhanced satellite data in ATOVS2 and ATOVS2_B experiments substantially increased the assimilated observations in this period. The HyMEX-SOP1 DTS campaign nicely contributed to better sample the Iberian Peninsula at 06 and 18 UTC, but some sensitive regions over North Africa remained un-sampled (neither by radiosondes nor aircraft observations). It should be noticed the existence of some frequent ASAPS close to the sensitive area located in the North Atlantic.

Looking at the most sensitive variables over the whole HyMeX-SOP1 (Table 5), in this period ATOVS2, followed by ATOVS2_B, present a clear improvement against CTRL, although their magnitudes are small, reaching in some cases a 5-6\%, and are not as significant as in the first 
period. DTS_RS shows still a smaller positive impact. Relative humidity at $700 \mathrm{hPa}$ is improved in all the DTEs.

Results of the verification of $24 \mathrm{~h}$ accumulated precipitation in this second period are shown in Figure 9b. It can be observed that all the DTEs systematically improve CTRL for all the precipitation thresholds, including for the intense ones $(>30 \mathrm{~mm} / 24 \mathrm{~h})$ and even for the heaviest ones $(>60 \mathrm{~mm} / 24 \mathrm{~h})$ when a non negligible number of stations recorded such amounts. ATOVS2 is again the experiment reaching the best scores, and it is remarkable that ATOVS2_B appears to behave better than DTS_RS.

Overall, the assimilation of additional ATOVS data in this period seems to have a positive impact, and in particular ATOVS2, the experiment that also assimilates extra radiosoundings, produces the maximum benefit with respect to CTRL.

\subsection{From 1 to 15 October: NAO+}

In this two-week period only a few heavy precipitation events were produced in the Western Mediterranean (IOPS 12ab and 13), which were embraced in 9 target times. Sensitive regions concentrated over the North Atlantic to the west of the British Islands, the Iberian Peninsula and the Western Mediterranean, and present a NW-SE pattern (Figure 6c). The Mediterranean sensitive region was sampled by DTS radiosondes and also by aircraft vertical profiles (not shown). ATOVS data density was doubled in the North Atlantic region in experiments ATOVS2 and ATOVS2_B. As in the Atlantic ridge period, in the baseline experiment this area was already sampled by upperlevel AMDAR data, and also by a few ASAPs, in addition to the ATOVS observations that are normally thinned. 
Table 5 shows that, according to the most sensitive parameters during the whole SOP1, DTS_RS is the only experiment that shows a consistent significant improvement with respect to CTRL, but small (maximum impact of $5 \%$ ). ATOVS2 and ATOVS2_B present a smaller impact that it is mostly negative (ATOVS2) but not statistically significant.

Verification scores for $24 \mathrm{~h}$ precipitation show that all the DTEs are able to improve CTRL in all the precipitation amounts. For light to moderate precipitation $(1-10 \mathrm{~mm} / 24 \mathrm{~h}$ thresholds) ATOVS2 behaves the best, but for intense precipitation $(>30 \mathrm{~mm} / 24 \mathrm{~h})$ ATOVS2_B is the experiment reaching slightly higher scores (Figure 9c).

For this period, it seems that the assimilation of targeted data is able to improve CTRL forecast. DTS_RS experiment behaves the best according to verification against analyses, but verification for observed precipitation reveals the important role of enhanced satellite data.

\subsection{From 16 to 26 October: Blocking}

During this period, the large-scale weather regime was favourable to an orographic precipitation event (IOP 14) and some heavy precipitation events (IOPS 15abc and 16a), which affected all the SOP1 regions. As a consequence, 16 targeting cases were deployed. Sensitive regions were located following a SW-NE pattern, along a sharp upper-level trough centred to the west of Iberia, covering the Western Mediterranean and Northern Africa, with maxima in the advance of the through over this continent (see Figure 6d). Figure 8 shows the spatial distribution of the observation types assimilated by the baseline and the DTEs experiments. The Western Mediterranean (including the Iberian Peninsula) was sampled by DTS radiosondes, as well as for AMDAR vertical profiles (at least the northern edge). ATOVS2 and ATOVS2_B assimilated double density of ATOVS data to 
better characterise the up-stream through over oceanic, data-poor areas, and the Mediterranean. Wide sensitive areas over Northern Africa were not surveyed.

Table 5 shows that, in this period, all DTEs improve CTRL for the most sensitive parameters found for the whole SOP1. The impact reaches a $12 \%$ for geopotential height at $700 \mathrm{hPa}$ of ATOVS2_B experiment. Experiments that produce the largest benefit (and statistically significant REL_RMSEs in some cases) in these parameters are ATOVS2 and ATOVS2_B, the DTEs that assimilated additional satellite data.

The results of the verification against daily rain gauge are displayed in Figure 9d. It shows that the experiments that only assimilated one single observation type as targeted data, either radiosoundings or satellite radiances, are able to improve CTRL for light to moderate precipitation (1-10 $\mathrm{mm} / 24 \mathrm{~h}$ thresholds). During this period a non-negligible number of stations recorded intense and heavy precipitation (30-60 $\mathrm{mm} / 24 \mathrm{~h}$ thresholds). However, no DTE improve CTRL for these precipitation amounts.

In summary, with respect to vertical profile of atmospheric variables, it seems that targeted data have a positive impact in this period, satellite observations the most. However, intense and heavy rain is not improved by them.

\subsection{From 27 October to 6 November: NAO-}

The last period of SOP1 was also favourable to heavy precipitation events (IOPs 16c, 18 and 19). However, only 6 targeted cases could be deployed due to budgetary reasons. In this short period (27 to 31 October) the upper-level trough did not moved southwards of $30^{\circ} \mathrm{N}$, as it did during the first $\mathrm{NAO}-$ period, and sensitive regions were most often located over Western Mediterranean and the 
North Atlantic, to the west of the Iberian Peninsula and around the British Islands (Figure 6e). Sensitive regions over or close to these land areas are well sampled for at least two different observing types, as radiosondes, aircraft profiles or ATOVS data (not shown). ATOVS2 and ATOVS2_B experiments increased the number of satellite data assimilated in these areas but also in other sparse data oceanic regions (not shown).

Table 5 reveals that, in this period, experiments that assimilated extra radiosoundings improved CTRL in the most sensitive parameters identified for the whole SOP1 period (experiments DTS_RS, followed by ATOVS2). REL_RMSEs were mostly negative for ATOVS2_B. The maximum benefit almost reaches a $10 \%$. The influence of the targeted data for relative humidity at $500 \mathrm{hPa}$ is either neutral (DTS_RS) or negative (rest of DTEs).

Verification of daily precipitation shows that ATOVS2 experiment behaves slightly better than the rest for up to $10 \mathrm{~mm} / 24 \mathrm{~h}$, and DTS_RS is the only one that outperforms CTRL for intense and heavy precipitation (see Figure 9e).

In a general sense, in this period, the assimilation of extra radiosoundings proves to have a positive impact, but the further enhancement of ATOVS data in sensitive areas reduces the benefit reached (except for light to moderate precipitation). When only enhanced satellite data are assimilated, the impact seems to be detrimental.

\section{Conclusions and discussion}

This work contributes to explore an adaptive observing system with terrestrial and space-based components, with the aim to improve the NWP skill in the Mediterranean. Four HIRLAM experiments (CTRL and three DTEs) have been conducted to test the influence of targeted 
observations on short-term forecasts of high-impact weather events over the HyMeX-SOP1. A baseline system including conventional and satellite (ATOVS radiances) observations has been defined. DTEs assimilate as targeted observations extra radiosoundings deployed during the HyMeX SOP1 campaign, and enhanced satellite observations located in sensitive areas identified by SAPs. The two different types of targeted observations have been added to the baseline first separately and then jointly. The main findings of the assessment are:

- In general, targeted observations have a positive but small impact on the short-term forecasts, noticeably at $700-500 \mathrm{hPa}$ in all parameters and precipitation. We find more and larger statistically significant improvements than degradations with respect to CTRL.

- DTS radiosoundings produce a clear overall improvement of HIRLAM forecasts.

- Data targeting based only on satellite observations has a generally positive impact on precipitation, and in short-term forecasts of the rest of parameters if compared against upper air observations.

- The assimilation of both types of extra observations produces the highest and most statistically significant improvement of HIRLAM forecasts.

- There is an overall agreement of the results obtained by the different verification methods employed, although the comparison of model forecasts against observations gives a larger positive impact to targeted data (and in particular to ATOVS observations) than the verification against IFS-ECMWF analyses.

- The magnitude of the impact on the forecasts depends on the weather regime that determines the location of sensitive areas.

- Satellite observations for data targeting show to produce a clear benefit on the HIRLAM forecasts when sensitive areas are located in sparse data oceanic areas. 
- For most of the selected high-impact weather events during SOP1, the targeted data were assimilated very frequently, and it produced an effect on the first guess of the subsequent analyses.

- According to the diagnostics obtained from the data assimilation cycle, the impact of targeted data on the first guess shows to be larger than the found on the longer lead-time forecasts.

- Extra radiosoundings assimilated at 06 and 18 UTC have a dominant positive impact on the first guess over the Iberian Peninsula and its surroundings.

- Enhanced satellite data assimilated are responsible for decreased background departures of brightness temperatures and radiosonde data in sea areas, as observed in the diagnostics of the data assimilation cycle.

- An adaptive ATOVS data thinning increases considerably the volume of targeted data. The addition of more targeted data to the HIRLAM DA system, although they are located in sensitive areas, not always leads to the improvement of the model forecasts.

Although there is an overall agreement on the results by the different forecast assessment methods, the verification against radiosonde observations shows a more consistent behaviour in the vertical of geopotential height, temperature and relative humidity by the different experiments. When compared against TEMP observations, the three data targeting experiments clearly improve geopotential height from $700 \mathrm{hPa}$ upwards and temperature from mid levels to surface. Also the vertical profile of humidity of the experiment that assimilated both DTS radiosondes and enhanced satellite data clearly improves that of CTRL experiment. Verification of 12 and $24 \mathrm{~h}$ accumulated precipitation, based on a different set of observations, supports the benefit produced by this experiment that assimilated the largest amount of data. We can expect some discrepancies between the results obtained by the two verification methods. They might be due to the size of the verification area and the location of radiosondes, to the influence of the ECMWF first guess fields in its analysis, and to the own ECMWF data assimilation system. 
The 4DVar analysis method finds the atmospheric initial state that minimizes the distance to the different estimates (the first guess, and the observations available along a time window), weighted by its respective error covariances, and constrained by the forecast model. The diagnostics obtained to check the performance of the data assimilation cycle reveal that the high frequency and number of targeted data had an impact on the first guess of the subsequent analyses that is still larger than that found in the high-impact weather forecasts. The reason why this impact becomes smaller deserves further investigation, but the fact that not all the sensitive regions were fully sampled could be partially responsible for it.

It is found that DTS radiosondes are able to reduce the magnitude of background departures over the Iberian Peninsula and its surroundings, and that extra satellite data have a negligible effect there. It might be due to the lowest values assigned to radiosonde observation errors in the HIRLAM 4DVar system. This leads to a larger weight of these data in the analysis if compared to other observation types. As it has been said, the Iberian Peninsula and its surroundings were the most frequent sensitive regions during HyMeX-SOP1, and the DTS campaign successfully deployed EUCOS radiosondes there at the targeting times. Routinely, there is not a high upper air observations density in this region at 06 and 18 UTC, especially for humidity. It explains the positive impact found by the experiment that only assimilated DTS radiosoundings.

In sensitive maritime areas both satellite radiances and the few available radiosonde data indicate the relevance of the addition of a high number of small weight satellite data to improve the data assimilation cycle. The experiment that assimilated both types of targeted data benefited from a better description of the initial state in broader sensitive regions: the Iberian Peninsula and surroundings due to DTS radiosondes, and in oceanic areas thanks to an increased satellite data volume. 
If we analyse separately the different periods of the whole HyMeX-SOP1, the impact on HIRLAM forecasts increases, and seems to respond to the location of the sensitive areas, the assimilated targeted data, the nearby observations in these regions, and the HIRLAM data assimilation system characteristics, including the data selection procedures.

HIRLAM experiments enhancing ATOVS data density in sensitive areas have shown that there is a high potential for targeting in the data thinning algorithms used that could be explored for the improvement of model forecasts. Our results show that the assimilation of additional satellite observations has a positive impact when the sensitive regions are mostly located in the North Atlantic to the south of $45^{\circ} \mathrm{N}$, in sparse data areas (first NAO- and Blocking periods). In these two HyMex periods, there occurred more than 55\% cases and the largest rain amounts were produced. The enhancement of ATOVS data selection, as the only source of targeted observations, has a considerable positive impact in geopotential height during the Blocking period. The experiment that assimilates both types of targeted data outperforms the rest and seems to indicate an overall good interaction between the terrestrial and the space-based adaptive observing systems. Precipitation scores systematically improve with the progressive addition of extra observations in sensitive areas that are normally sparse data regions, as it is the case of the first NAO- period. Nevertheless, large target regions that are routinely data void areas, were not completely surveyed (especially during the Blocking period). This was the case of North Africa. In this Blocking period none of the experiments is able to improve CTRL for intense and heavy precipitation amounts.

The aim of data targeting is to reduce the forecast error by the addition of new observations, but it does not always happen. Apart of the incomplete sampling of sensitive areas, data assimilation methods are imperfect due to different reasons, among them, to deficiencies in background and observation error statistics. DTS radiosoundings during HyMeX-SOP1 increased moderately the 
total number of data assimilated (15\% approximately) and were mostly located in mid-low observation density areas. Its impact is mostly positive but smaller than the obtained with satellite targeted data. The adaptive ATOVS data thinning augmented considerably the volume of targeted observations. The meteorological patterns that followed were responsible for the location of the different target areas beyond Iberia and its surroundings. During some periods (Atlantic Ridge, $\mathrm{NAO}+$ and the last $\mathrm{NAO}-$ period) sensitive areas reached well sampled regions to the north of the Iberian Peninsula. In the Atlantic Ridge and last NAO- periods, the results obtained might indicate that the addition of more satellite observations there is not optimal (see e.g. the REL_RMSEs of the different experiments and scores for precipitation). The diagnostics of the data assimilation cycle obtained also seem to indicate that the combination of the new with the existing data in some areas could be improved. In these experiments we have adopted a very crude approach for the adaptive satellite observations selection, without taking into account the existence of nearby observations coming from other sources. Introducing large amount of data, as satellite soundings without a further tuning of the data assimilation system, may produce a detrimental effect.

The potential impact of data targeting also depends on how predictable is the atmospheric flow. The largest decrease of background departures due to the assimilation of targeted data is found in those regions with the poorest first guess. Also, in HyMeX-SOP1, the highest RMSE of geopotential height at $500 \mathrm{hPa}$ (averaged in the verification area) was reached during the last NAOperiod $(13.0 \mathrm{~m})$, followed by the Blocking and first NAO- episodes $(9.0$ and $9.3 \mathrm{~m})$. The lowest RMSE values of geopotential height at $500 \mathrm{hPa}$ corresponded to the Atlantic Ridge and NAO+ weather regimes $(4.9$ and $5.8 \mathrm{~m})$. The results obtained show that the benefit in mass and wind fields produced by targeted radiosonde observations (experiment DTS_RS) increases with the error magnitude, and almost reaches a $10 \%$ during the less predictable period (last NAO- episode). 
Our impact study results agree with other data targeting evaluations in the extratropics, which have been compiled by Majumdar et al. (2011), and in particular with data targeting experiments carried out recently by Campins et al. (2013) over high-impact weather events in the Mediterranean during the past DTS-PREVIEW-2008 and DTS-MEDEX-2009. Recent impact studies with global NWP systems showed generally a neutral impact (Hamill et al., 2013). Hamill et al. (2013) explained this smaller impact than the one reported in previous targeted observation studies, most from over a decade ago, by improved forecast and data assimilation systems and denser observation network. They also highlight that the neutral impact they obtain might be due to an undersampling of the sensitive areas and propose for mid latitudes a different concept of data targeting based on the assimilation of a denser set of satellite data in dynamically sensitive areas. The HIRLAM experiments conducted over HyMeX-SOP1 that are based on this approach have shown the positive impact obtained by enhanced ATOVS data assimilated in sparse data oceanic areas, in agreement with the results obtained for DTS-PREVIEW-2008 and DTS-MEDEX-2009 (Campins et al., 2013).

\section{Acknowledgements}

This work is a contribution to the HyMeX programme. The DTS impact study described here is part of the Working Plan of the HyMeX Science team devoted to advance data assimilation and ensemble prediction systems to improve forecasts of high-impact weather events in Mediterranean. The authors acknowledge the EUCOS observation program of the European Consortium of National Meteorological Services (EUMETNET) for its financial support of HyMeX-SOP1 field campaign agreed in the Memorandum of Understanding between EUMETNET and the HyMeX program. Participants in HyMeX-SOP1-DTS from Météo-France and AEMET as case proposals and final decison for targeting are also acknowledged. We also thank to Javier Calvo, who gave us support for the verification of HIRLAM forecasts against rain-gauge data. This work has been partially supported by PREDIMED (CLI-CGL2011-24458) project. 


\section{References}

Bauer P, Buizza R, Cardinali C, Thépaut, J-N. 2011. Impact of singular-vector-based satellite data thinning on NWP, Q. J. Roy. Meteor. Soc., 137, 286-302, doi:10.1002/qj.733.

Campins J, Navascués B, Santos C, Amo-Baladrón A. 2013: Influence of targeted observations on short-term forecasts of high-impact weather events in the Mediterranean. Nat. Hazards Earth Syst. Sci., 13, 2891-2910, doi:10.5194/nhess-13-2891-2013.

Cassou C, Terray L, Hurrell JW, Deser C. 2004. North Atlantic winter climate regimes: Spatial asymmetry, stationarity with time, and oceanic forcing. J. Climate, 17, 1055-1068, doi: 10.1175/1520-0441(2004)017<1055:NAWCRS>2.0.CO;2.

Drobinski P, Ducrocq V, Alpert P, Anagnostou E, Béranger K, Borga M, Braud I, Chanzy A, Davolio S, Delrieu G, Estournel C, Filali Boubrahmi N, Font J, Grubišić V, Gualdi S, Homar V, Ivanćan-Picek B, Kottmeier C, Kotroni V, Lagouvardos K, Lionello P, Llasat MC, Ludwig W, Lutoff C, Mariotti A, Richard E, Romero R, Rotunno R, Roussot O, Ruin I, Somot S, TaupierLetage I, Tintore J, Uijlenhoet R, Wernli H. 2014: HyMeX: A 10-Year Multidisciplinary Program on the Mediterranean Water Cycle. Bulletin of the American Meteorological Society, 95, 10631082. doi: 10.1175/BAMS-D-12-00242.1.

Ducrocq V, Doerenbecher A, Fourrié N, Nuret M, Campins J, Navascués B. 2014a. Final Report on the impact of DTS observations during HyMeX SOP1, Reference: Memorandum of Undersatnding between EUMETNET and the HyMeX program. 29 December 2014.

Ducrocq V, Braud I, Davolio S, Ferretti R, Flamant C, Jansà A, Kalthoff N, Richard E, TaupierLetage I, Ayral PA, Belamari S, Berne A, Borga M, Boudevillain B, Bock O, Boichard JL, Bouin MN, Bousquet O, Bouvier C, Chiggiato J, Cimini D, Corsmeier U, Coppola L, Cocquerez P, Defer E, Delanoë J, Di Girolamo P, Doerenbecher A, Drobinski P, Dufournet Y, Fourrié N, Gourley JJ, Labatut L, Lambert D, Le Coz J, Marzano FS, Molinié G, Montani A, Nord G, Nuret M, Ramage K, Rison B, Roussot O, Said F, Schwarzenboeck A, Testor P, Van-Baelen J, Vincendon B, Aran M, 
Tamayo J. 2014b. HyMeX-SOP1, the field campaign dedicated to heavy precipitation and flash flooding in the northwestern Mediterranean. Bulletin of the American Meteorological Society, 95, 1083-1100. doi:10.1175/BAMS-D-12-00244.1 (electronic supplement: http://journals.ametsoc.org/doi/suppl/10.1175/BAMS-D-12-00244.1/suppl_file/10.1175 bams-d12-00244.2.pdf).

Ferretti R, Pichelli E, Gentile S, Maiello I, Cimini D, Davolio S, Miglietta MM, Panegrossi G, Baldini L, Pasi F, Marzano FS, Zinzi A, Mariani S, Casaioli M, Bartolini G, Loglisci N, Montani A, Marsigli C, Manzato A, Pucillo A, Ferrario ME, Colaiuda V, Rotunno R. 2014. Overview of the first HyMeX Special Observation Period over Italy: observations and model results, Hydrol. Earth Syst. Sci., 18, 1953-1977, doi:10.5194/hess-18-1953-2014.

Gustafsson N, Huang XY, Yang X, Mogensen K, Lindskog M, Vignes O, Wilhelmsson T, Thorsteinsson S. 2012. Four-dimensional variational data assimilation for a limited area model, Tellus A, 64, 14985, doi:10.3402/tellusa.v64i0.14985.

Hally A, Richard E, Ducrocq V. 2014. An ensemble study of HyMeX IOP6 and IOP7a: sensitivity to physical and initial and boundary condition uncertainties. Nat. Hazards Earth Syst. Sci., 14, 1-14, 2014, doi:10.5194/nhess-14-1-2014.

Hamill TM, Yang F, Cardinali C, Majumdar SJ. 2013. Impact of Targeted Winter Storm Reconnaissance Dropwindsonde Data on Midlatitude Numerical Weather Predictions. Mon. Wea. Rev., 141, 2058-2065.

Irvine EA, Gray SL, Methven J. 2011. Targeted observations of a polar low in the Norwegian Sea. Q. J. R. Meteorol. Soc. 137: 1688-1699. DOI:10.1002/qj.914.

Jansà A, Arbogast P, Doerenbecher A, Garcies L, Genovés A, Homar V, Klink S, Richardson D, Sahin C. 2011. A new approach to sensitivity climatologies: the DTS-MEDEX-2009 campaign, Nat. Hazards Earth Syst. Sci., 11, 2381-2390, doi:10.5194/nhess-11-2381-2011. 
Jansà A, Campins J, Picornell MA, Guijarro JA. 2014. Heavy rain and strong wind events over Spain during HyMeX SOP1, Thetys, Revista de meteorologia i climatologia mediterrània, 11, 25-38.

Kain JS. 2004. The Kain-Fritsch Convective Parameterization: An Update, J. Appl. Meteor., 43, 170-181, doi:10.1175/1520-0450(2004)043<0170:TKCPAU>2.0.CO;2.

Kim HM, Kim S-M, Jung B-J. 2011. Real-Time Adaptive Observation Guidance Using Singular Vectors for Typhoon Jangmi (200815) in T-PARC 2008. Wea. Forecasting, 26, 634-649. doi: http://dx.doi.org/10.1175/WAF-D-10-05013.1.

Langland RH. 2005. Issues in targeted observing, Q. J. Roy. Meteor. Soc., 131, 3409-3425, doi:10.1256/qj.05.130.

Lindskog M, Gustafsson N, Navascués B, Mogensen K-S, Huang X-Y, Yang X, Andrae U, Berre L, Thorsteinsson S, Rantakokko J. 2001. Three-dimensional variational data assimilation for a limited area model. Part II: Observation handling and assimilation experiments. Tellus, 53 A, 447468. doi: 10.1111/j.1600-0870.2001.00447.x.

Majumdar SJ, Aberson SD, Bishop CH, Cardinali C, Caughey J, Doerenbecher A, Gauthier P, Gelaro R, Hamill TM, Langland RH, Lorenc AC, Nakazawa T, Rabier F, Reynolds CA, Saunders R, Song Y, Toth Z, Velden C, Weissmann M, Wu CC. 2011. Targeted observations for improving numerical weather prediction: an overview, World Weather Research Programme/THORPEX Publication No. 15, 37 pp. http://www.wmo.int/pages/prog/arep/wwrp/new/documents/THORPEX_No_15.pdf.

Prates C, Richardson D, Sahin C. 2009. Final report of the PREVIEW observation Data Targeting System (DTS). ECMWF Tech. Memo., 581, 31.

Schyberg H, Landelius T, Thorsteinsson S, Tveter FT, Vignes O, Amstrup B, Gustafsson N, Harvinen H, Lindskog M. 2003. Assimilation of ATOVS Data in the HIRLAM 3-D-Var System. HIRLAM Tech. Rep. Nr 60, available at: 
http://www.hirlam.org/index.php?option=com_docman\&task $=$ doc_download\&gid=260\&Itemid=71

Undén P, Rontu L, Järvinen H, Lynch P, Calvo J, Cats G, Cuxart J, Eerola K, Fortelius C, García-Moya J-A, Jones C, Lenderlink G, McDonald A, McGrath R, Navascués B, Nielsen N-W, Odegaard V, Rodríguez E, Rummukainen M, Rõõm R, Sattler K, Sass B-H,Savijärvi H, Schreur BW, Sigg R, The H, Tijm A. 2002. HIRLAM-5 Scientific Documentation, available from SMHI, S60176 Norrköping, Sweden.

Wilks D S. 2011. Statistical Methods in the Atmospheric Sciences, Volume 100, Third Edition (International Geophysics), Academic Press.

Zhang M, Lin W, Bretherton CS, Hack JJ, Rasch PJ. 2003. A modified formulation of fractional stratiform condensation rate in the NCAR Community Atmospheric Model (CAM2), J. Geophys. Res, 108, 4035, doi:10.1029/2002JD002523. 
Table 1: Targeted radiosondes assimilated and ATOVS thinning distance used in Control (CTRL) and Data Targeting Experiments (DTS_RS, ATOVS2_B and ATOVS2).

\begin{tabular}{lll}
\hline Experiment & Targeted radiosondes & ATOVS thinning \\
\hline CTRL & None & Normal $0.90^{\circ}$ \\
DTS_RS & DTS radiosondes & Normal $0.90^{\circ}$ \\
ATOVS2_B & None & Double $0.45^{\circ}$ \\
ATOVS2 & DTS radiosondes & Double $0.45^{\circ}$ \\
\hline
\end{tabular}


Table 2: For each Data Targeting Experiment (DTE): Mean relative RMSE (in \%) for geopotential height $(\mathrm{Z})$, temperature $(\mathrm{T})$, wind speed (SPD), and relative humidity $(\mathrm{RH})$ at some vertical levels. Statistically significant values are marked in bold and with an *.

\begin{tabular}{|c|c|c|c|}
\hline & DTS_RS & ATOVS2_B & ATOVS2 \\
\hline Z300 & 3.5 & 1.4 & -0.8 \\
\hline $\mathrm{Z} 500$ & 2.1 & 1.9 & 0.9 \\
\hline $\mathrm{Z700}$ & 2.6 & $4.4^{*}$ & 3.5 \\
\hline $\mathrm{Z} 850$ & 1.1 & 0.9 & 0.5 \\
\hline Z925 & 0.6 & -0.3 & -0.3 \\
\hline T300 & 1.2 & -0.3 & 2.7 \\
\hline T500 & 0.6 & 0.6 & -0.1 \\
\hline T700 & 0.1 & 1.6 & 1.0 \\
\hline T850 & -0.1 & -0.5 & -0.7 \\
\hline T925 & 0.8 & 0.1 & 0.0 \\
\hline SPD300 & 2.9 & -0.5 & -1.3 \\
\hline SPD500 & $3.8^{*}$ & 0.3 & $3.5^{*}$ \\
\hline SPD700 & -0.7 & 0.9 & 1.1 \\
\hline SPD850 & -1.4 & 0.2 & -0.8 \\
\hline SPD925 & -0.8 & -1.6 & -1.1 \\
\hline RH300 & 1.7 & -0.9 & -0.2 \\
\hline RH500 & 2.1 & 1.3 & $3.3 *$ \\
\hline RH700 & $2.6 *$ & 0.2 & $3.2 *$ \\
\hline RH850 & -0.7 & $-1.4 *$ & -1.0 \\
\hline RH925 & $-1.3^{*}$ & -0.5 & 0.5 \\
\hline
\end{tabular}


Table 3: Mean relative RMSE (in \%) for mean sea level pressure (MSLP) for DTS_RS, ATOVS and ATOVS2_B experiments against SYNOP reports ( $\mathrm{N}$ is the number of observations).

\begin{tabular}{lccccc}
\hline & Range & DTS_RS & ATOVS2_B & ATOVS2 & N \\
\hline MSLP & $\mathrm{H}+18$ & -0.41 & -0.12 & 0.81 & 9686 \\
& $\mathrm{H}+24$ & 0.28 & -0.57 & -0.28 & 10094 \\
& $\mathrm{H}+30$ & 1.92 & 3.15 & 0.91 & 7870 \\
& & & & & \\
\hline
\end{tabular}

Table 4: As Table 3 for 12-h accumulated precipitation (ACC. PCP.).

\begin{tabular}{lccccc}
\hline & Range & DTS_RS & ATOVS2_B & ATOVS2 & N \\
\hline ACC. PCP. & $\mathrm{H}+18$ & 6.04 & 4.86 & 2.64 & 1366 \\
& $\mathrm{H}+24$ & 1.67 & 1.75 & 1.57 & 17201 \\
& $\mathrm{H}+30$ & -0.53 & 7.48 & 2.75 & 1326 \\
& & & & & \\
\hline
\end{tabular}


Table 5: For each Data Targeting Experiment (DTE): Mean relative RMSE (in \%) for some selected parameters and for each period. Statistically significant values are marked in bold and with an *.

\begin{tabular}{|c|c|c|c|c|}
\hline & & DTS_RS & ATOVS2_B & ATOVS2 \\
\hline Atlantic ridge & $\mathrm{Z700}$ & 3.2 & -3.7 & 2.1 \\
\hline \multirow[t]{3}{*}{5 to 22 September } & SPD500 & $6.6^{*}$ & -0.3 & $9.4 *$ \\
\hline & RH700 & $9.0 *$ & -2.4 & $7.8 *$ \\
\hline & RH500 & -0.5 & -2.3 & 3.4 \\
\hline NAO- & $\mathrm{Z} 700$ & -0.8 & 6.4 & 5.2 \\
\hline \multirow[t]{3}{*}{23 to 30 September } & SPD500 & 1.0 & 2.1 & 4.1 \\
\hline & RH700 & 3.1 & 0.2 & $4.2 *$ \\
\hline & RH500 & 0.8 & 1.0 & 2.9 \\
\hline $\mathrm{NAO}+$ & $\mathrm{Z700}$ & -4.9 & 1.6 & -2.9 \\
\hline \multirow[t]{3}{*}{1 to 15 October } & SPD500 & $4.3 *$ & -2.1 & -0.5 \\
\hline & RH700 & $2.9 *$ & -0.1 & -1.1 \\
\hline & RH500 & $5.4 *$ & 1.8 & 0.9 \\
\hline Blocking & $\mathrm{Z700}$ & 4.6 & $12.0 *$ & 4.7 \\
\hline \multirow[t]{3}{*}{16 to 26 October } & SPD500 & 2.2 & 1.5 & 1.4 \\
\hline & RH700 & -1.8 & 1.5 & 2.5 \\
\hline & RH500 & 3.3 & $5.9 *$ & $7.5^{*}$ \\
\hline NAO- & $\mathrm{Z700}$ & 9.7 & $-4.8 *$ & 4.2 \\
\hline 27 October to & SPD500 & $9.9 *$ & -2.3 & 6.5 \\
\hline \multirow[t]{2}{*}{6 November } & RH700 & $4.3 *$ & 0.6 & $4.2 *$ \\
\hline & RH500 & -0.6 & -7.2 & -4.1 \\
\hline
\end{tabular}


(a)

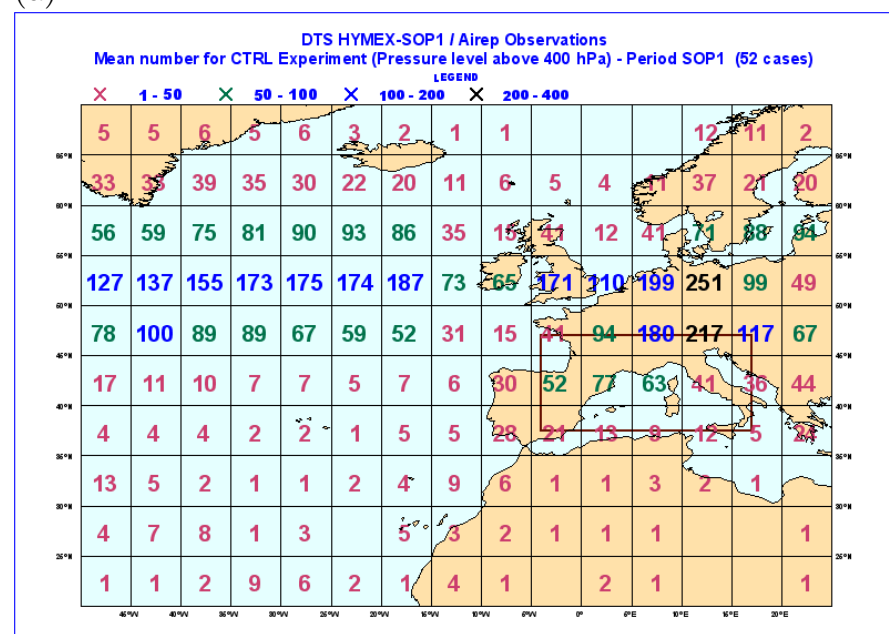

(c)

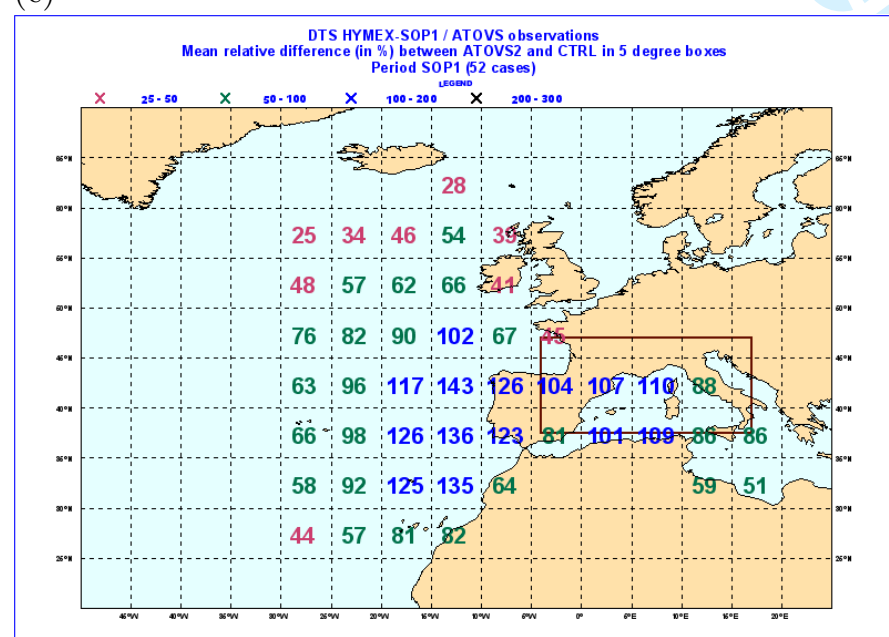

(b)

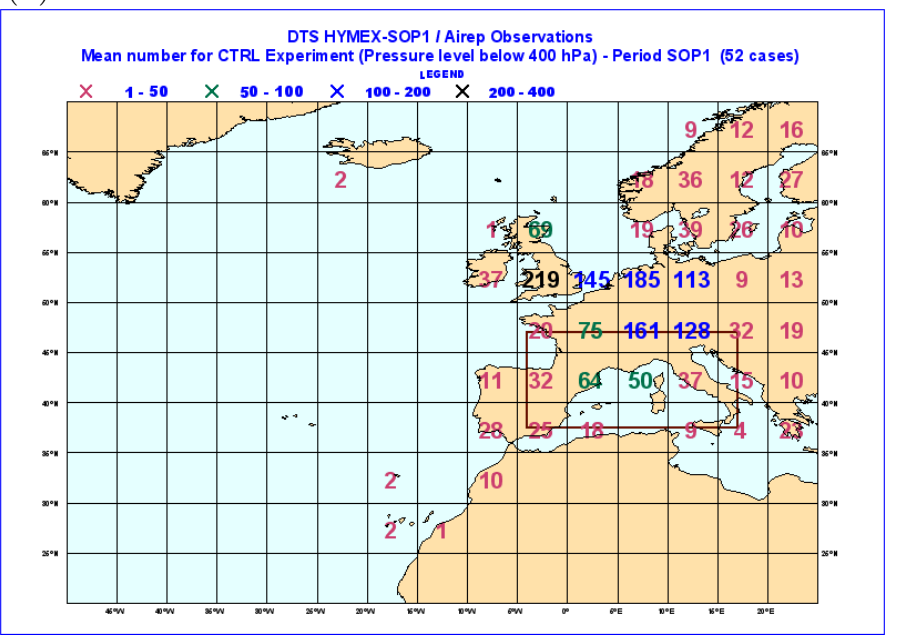

(d)

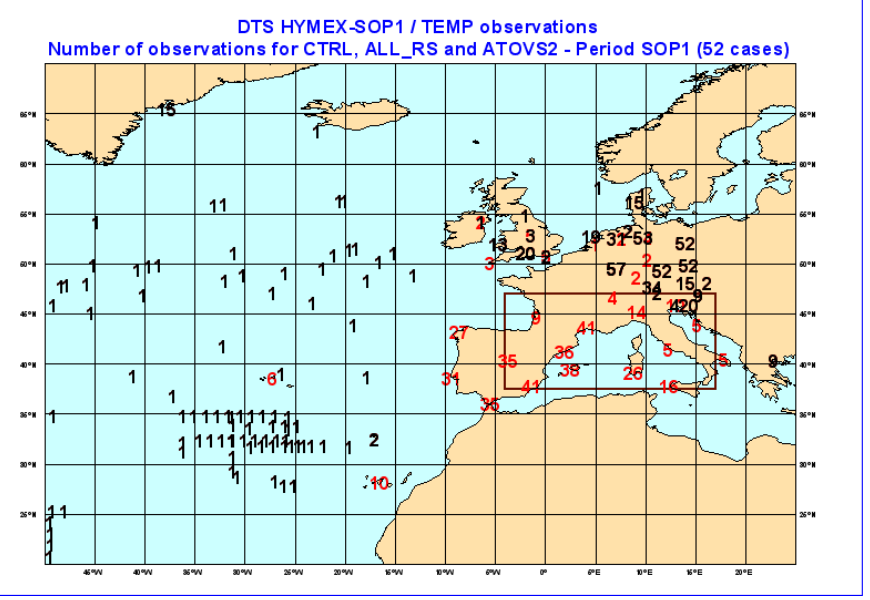

Figure 1: Spatial distribution of upper-air observations assimilated at the targeting times during HyMeX-SOP1:(a) Mean number of aircraft observations for data below $400 \mathrm{hPa}$, (b) the same for data above $400 \mathrm{hPa}$, (c) mean relative difference (in \%) of ATOVS data assimilated between ATOVS2/ATOVS2_B experiments and the baseline, and (d) number of operational (black) and DTS (red) radiosondes. Brown box indicates the Verification Area (VA). 
(a)

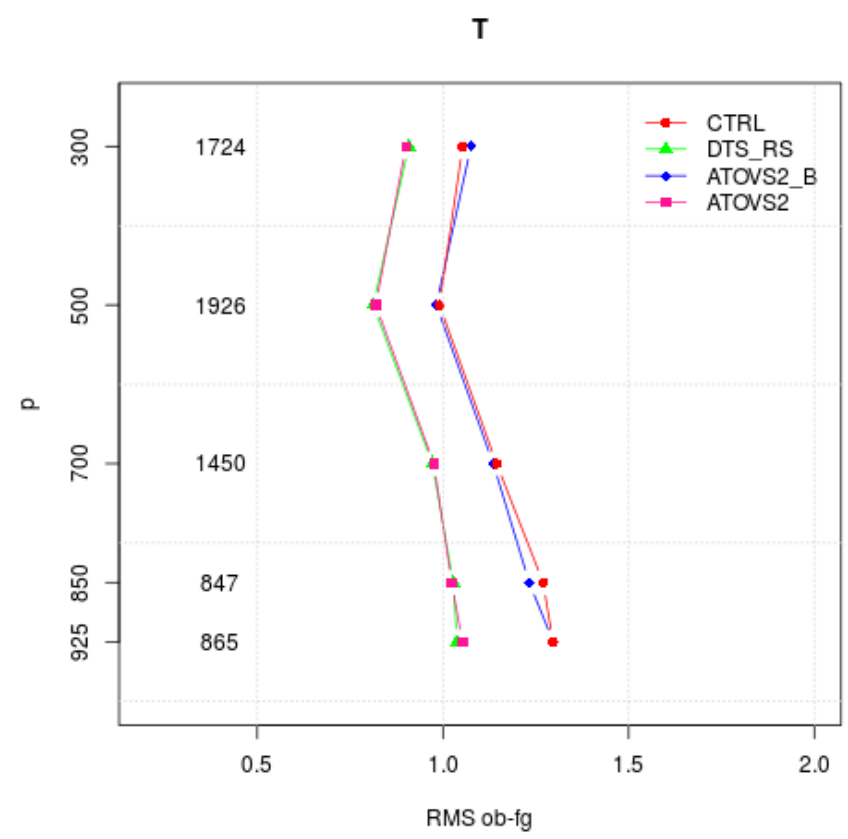

(c)

u

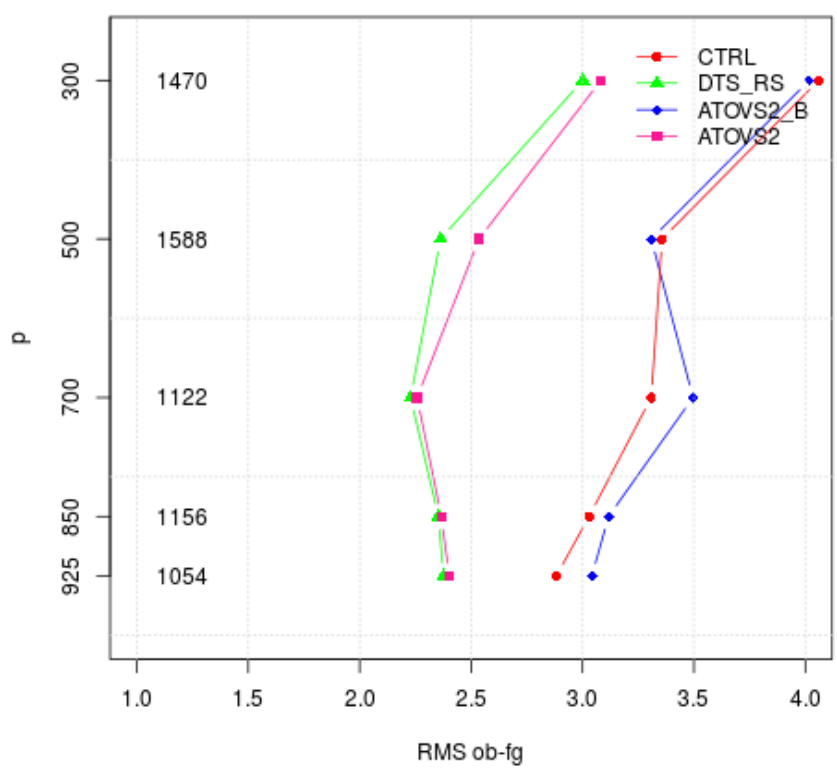

(b)

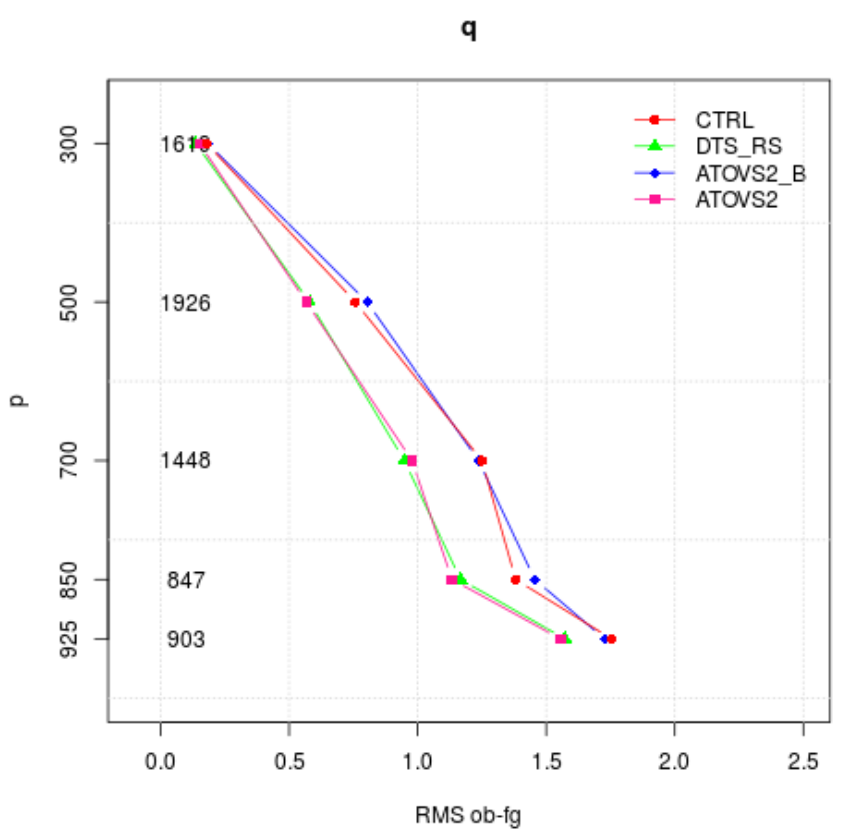

(d)

u

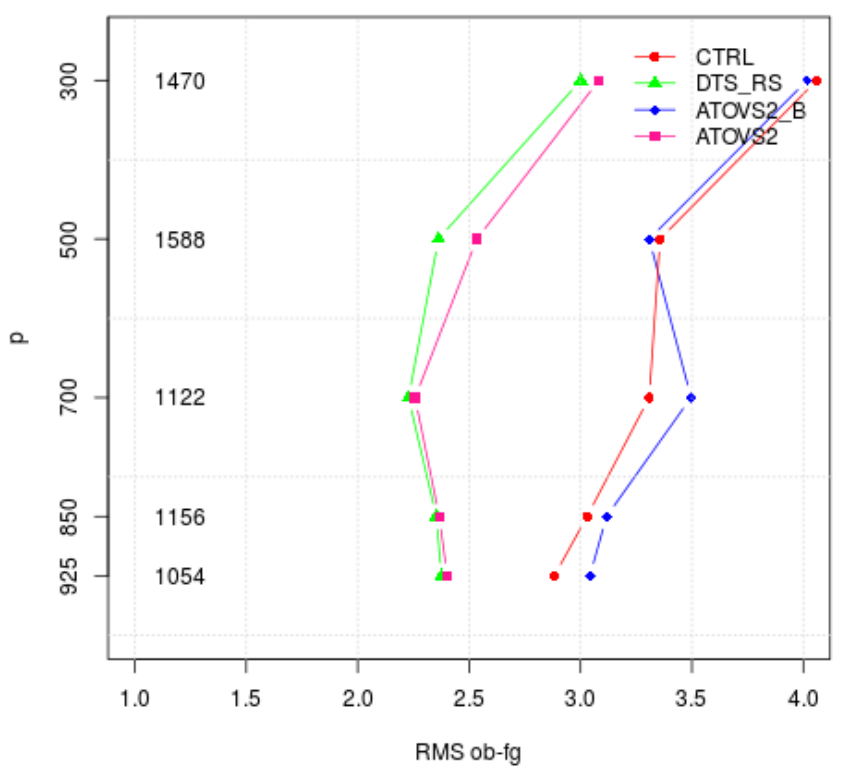

Figure 2: RMS of radiosonde observation minus first guess values for a region around the Iberian Peninsula (see text): (a) temperature (in $\mathrm{K}$ ), (b) specific humidity (in $\mathrm{g} / \mathrm{kg}$ ), and (c,d) horizontal wind components (in m/s). (a,b,c,d) show departures for CTRL (red), DTS_RS (green), ATOVS2_B (blue) and ATOVS2 (violet). To the right of y-axis the number of observations is displayed. 
(a)

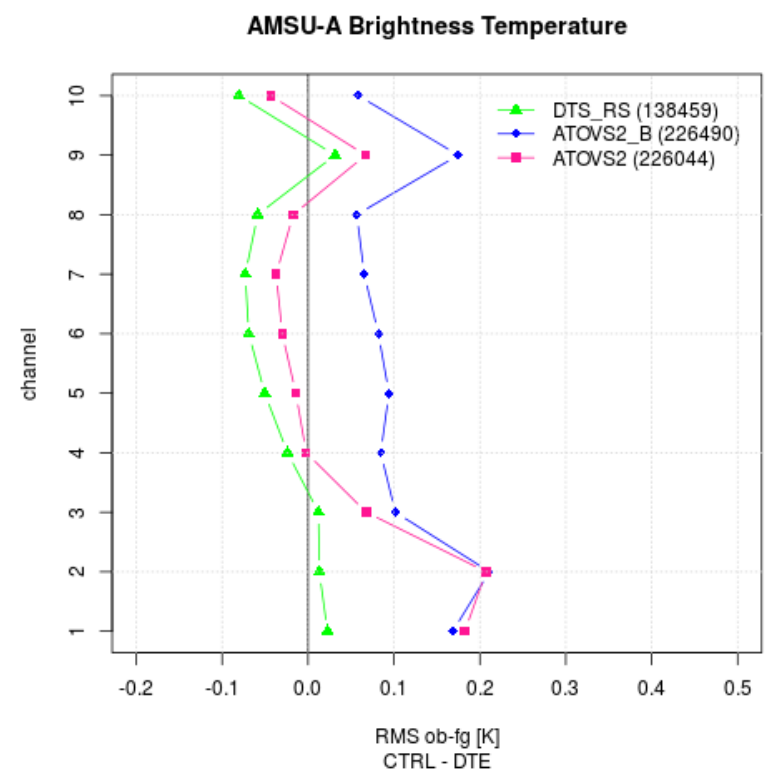

(b)

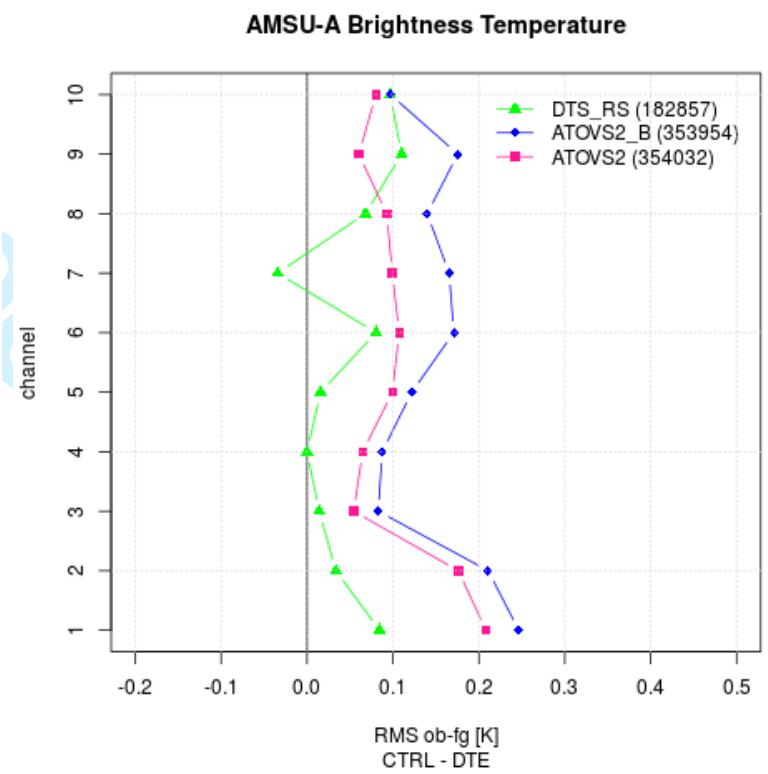

Figure 3: Differences with respect to CTRL of the RMS of AMSU-A brightness temperature innovations (in K) (DTS_RS in green, ATOVS2_B in blue and ATOVS2 in violet): (a) North Atlantic region northward of $45^{\circ} \mathrm{N}$, and (b) and North Atlantic region southward of $45^{\circ} \mathrm{N}$. Positive/negative values indicate smaller/higher innovations than CTRL. 
(a)

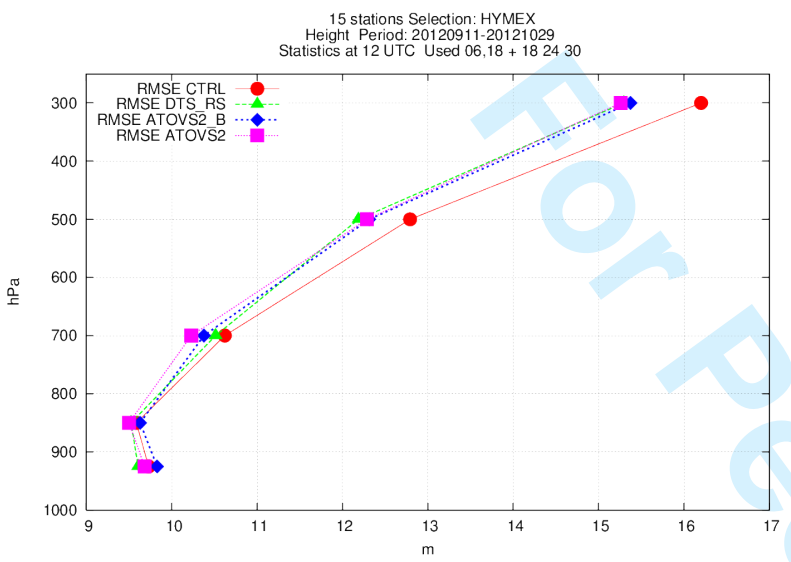

(c)

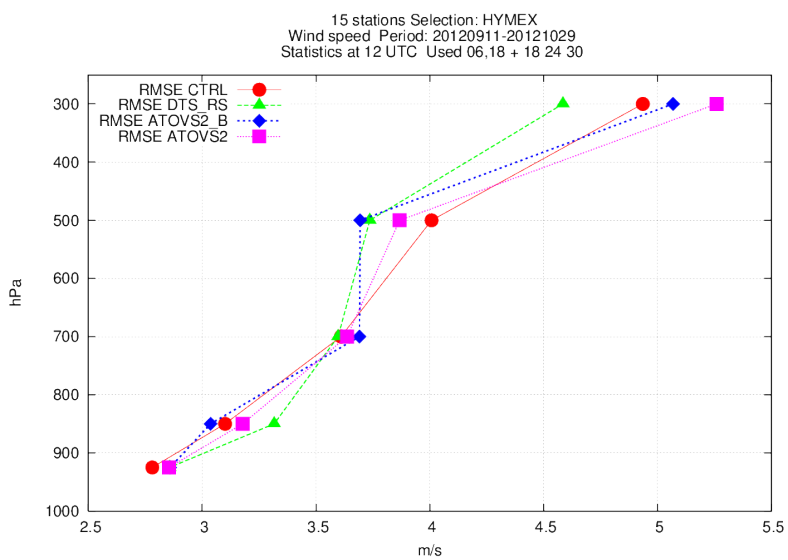

(b)

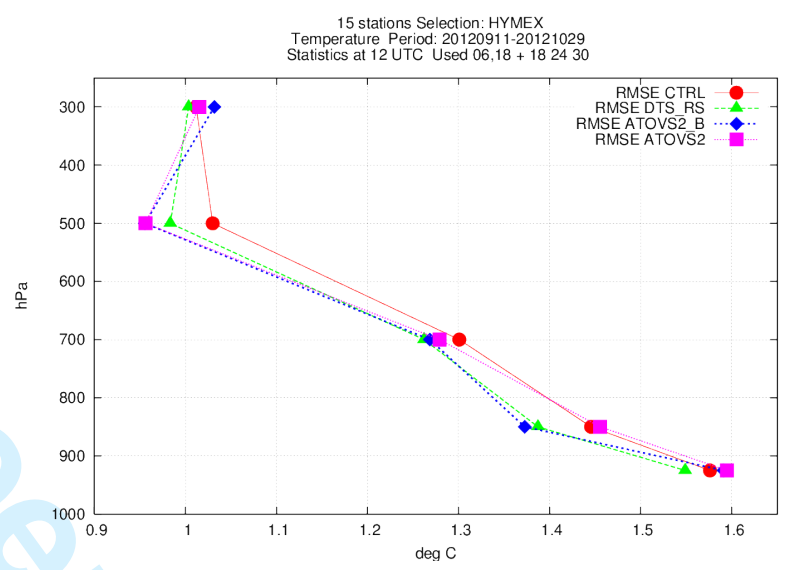

(d)

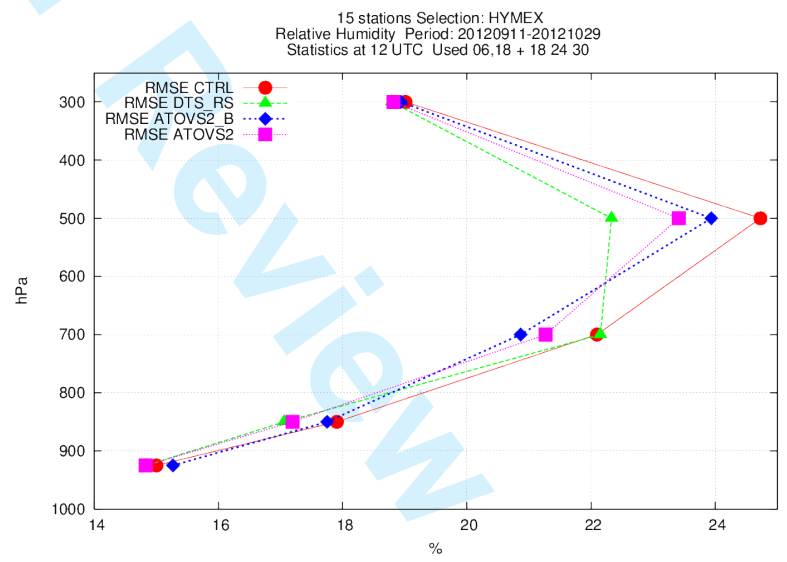

Figure 4: Verification against radiosondes: RMSE of CTRL (red), DTS_RS (green), ATOVS2_B (blue) and ATOVS2 (violet) forecasts: (a) geopotential height (in $\mathrm{m}$ ), (b) temperature (in degrees $\mathrm{C}$ ), (c) wind speed (in $\mathrm{m} / \mathrm{s}$ ), and (d) relative humidity (in \%). 
(a)

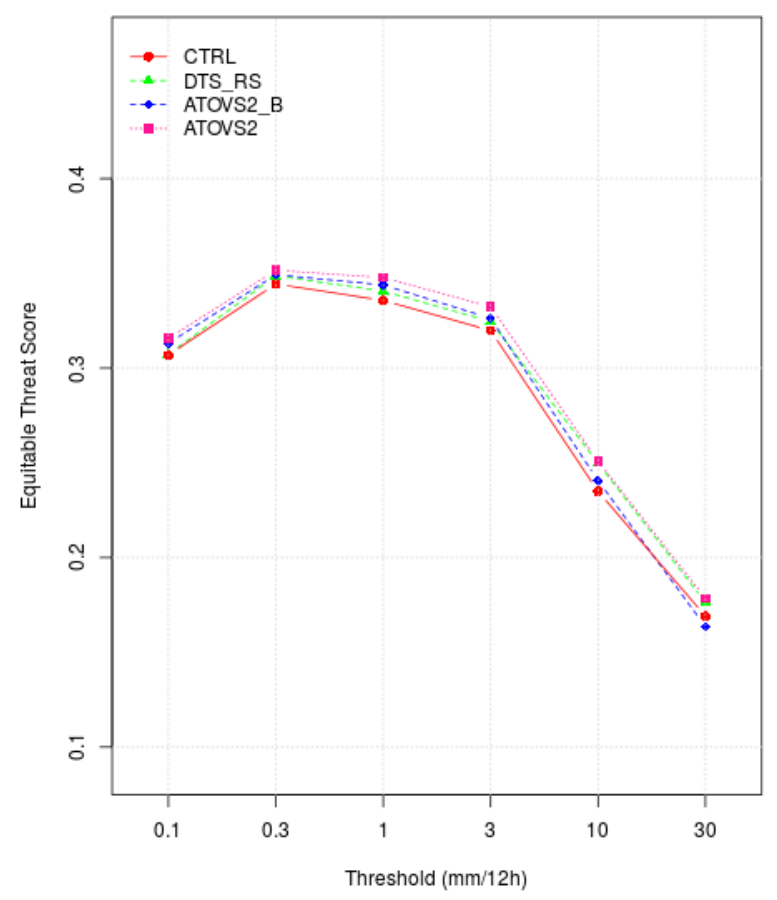

(b)

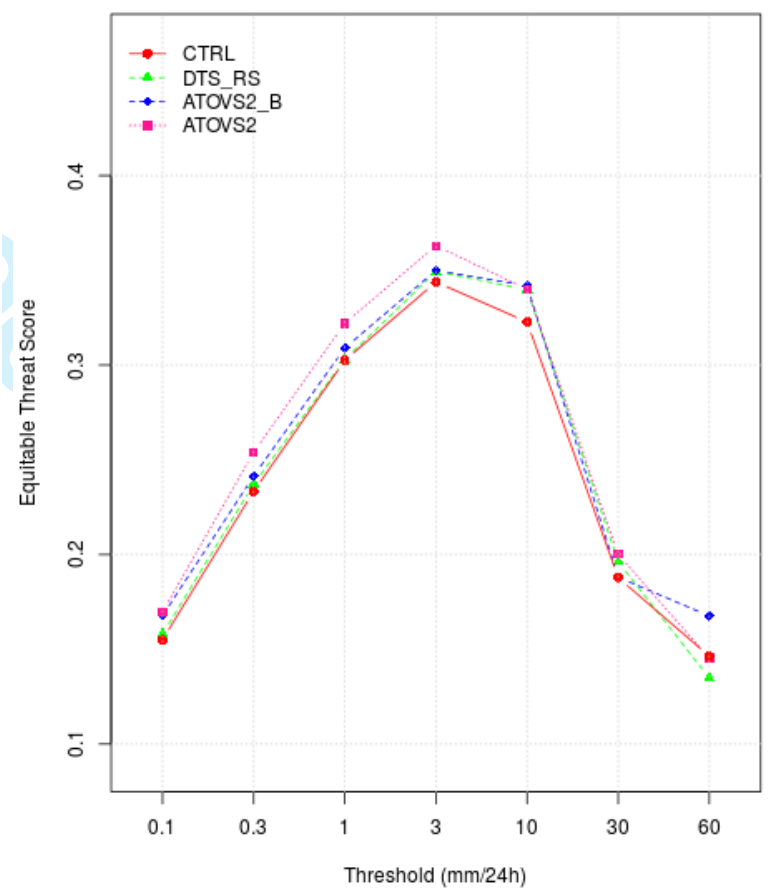

Figure 5: Equitable threat score for 12-h and 24-h accumulated precipitation (a and b) for all the cases registered during SOP1. Scores for CTRL (red), DTS_RS (green), ATOVS2_B (blue), and ATOVS2 (violet). 
(a)

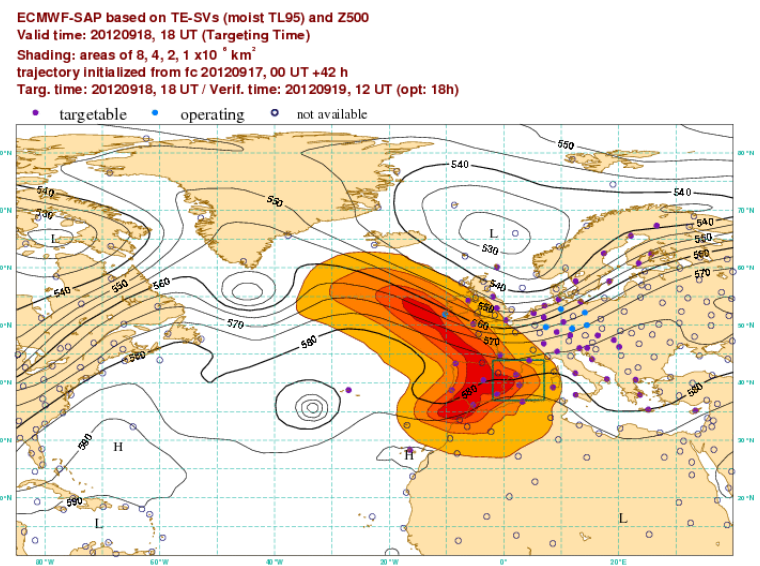

(c)

ECMWWF-SAP based on TE-SVs (molst TL.95) and 7500 Shadilig: areas ofts, $4,2,1 \times 10^{\circ} \mathrm{km}^{2}$ Tim

trajectory Intitilized from $1 \mathrm{c} 20121012,00 \mathrm{UT}+42 \mathrm{~h}$

Targ. time: 20121013, 18UT/Vent. lime: 20121014, 18 UT (opt: 24h)

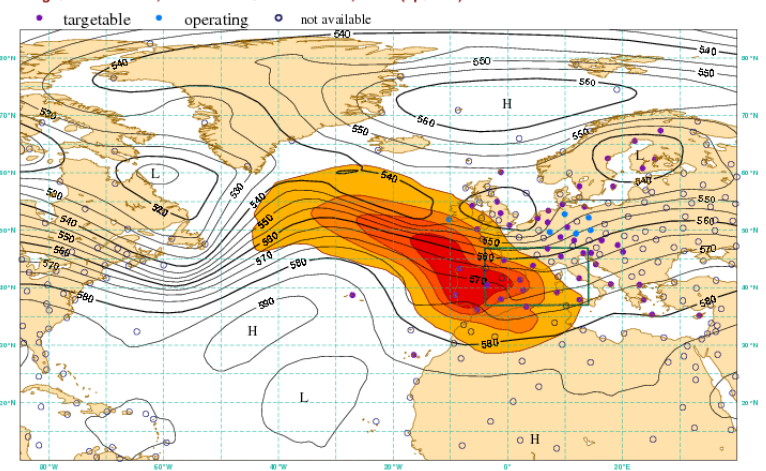

(e)

ECMWF-SAP based on TE-SVs (molst TL95) and 2500

Valid time: 20121029, 18 UT (Targeting Time)

of $8,4,2,1 \times 10^{\circ} \mathrm{km}^{2}$

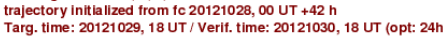

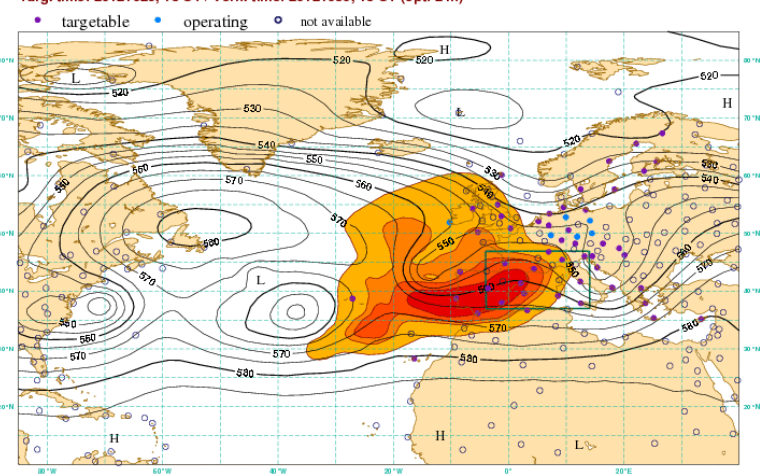

(b)

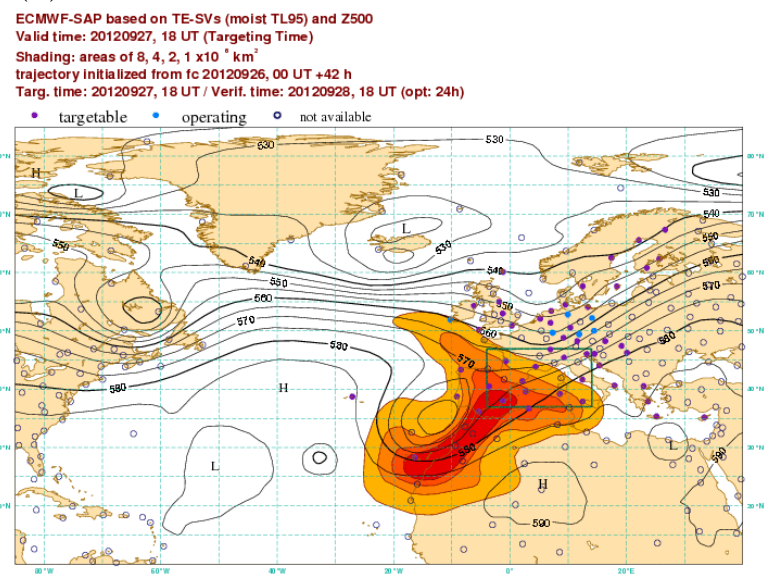

(d)

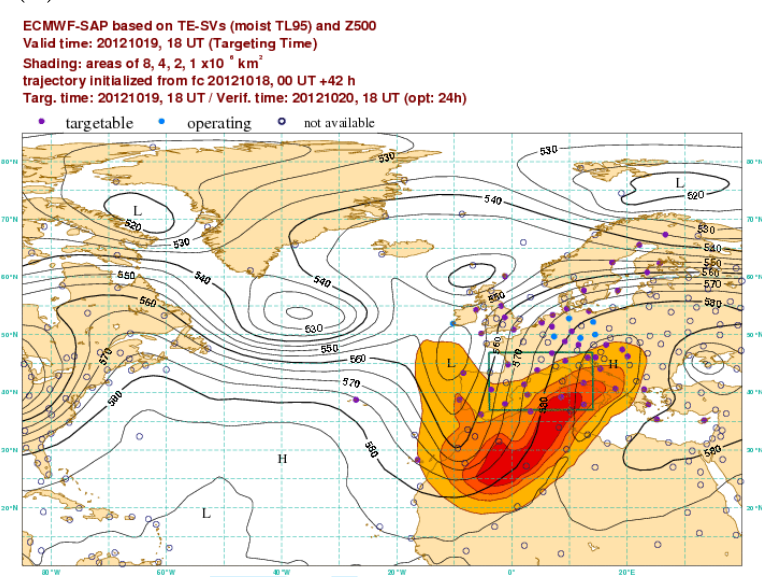

Figure 6: Sensitive Area Prediction for a representative case of each individual period: (a) Atlantic ridge, (b) first NAO-, (c) NAO+, (d) Blocking, and (e) second NAO-. 
(a)

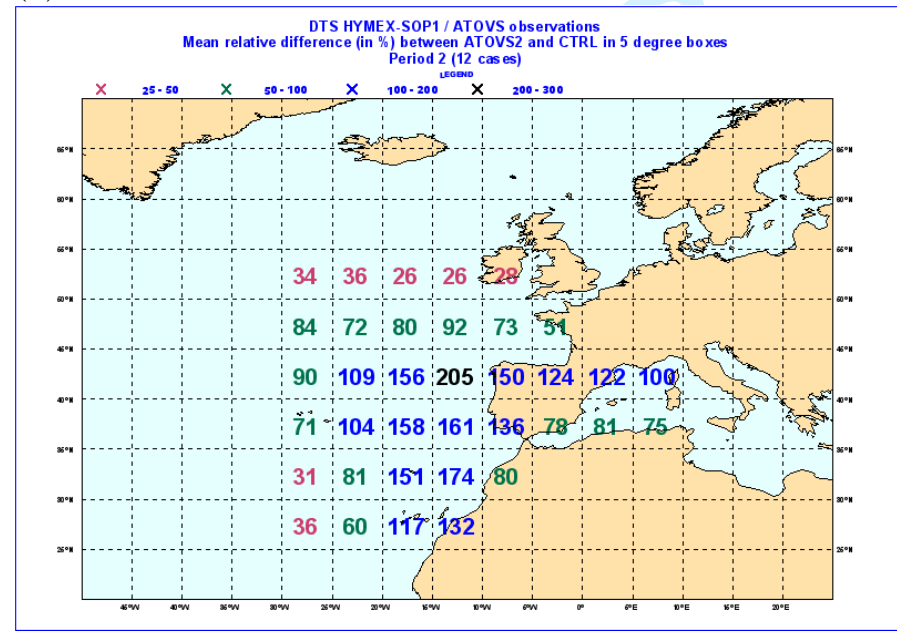

(b)

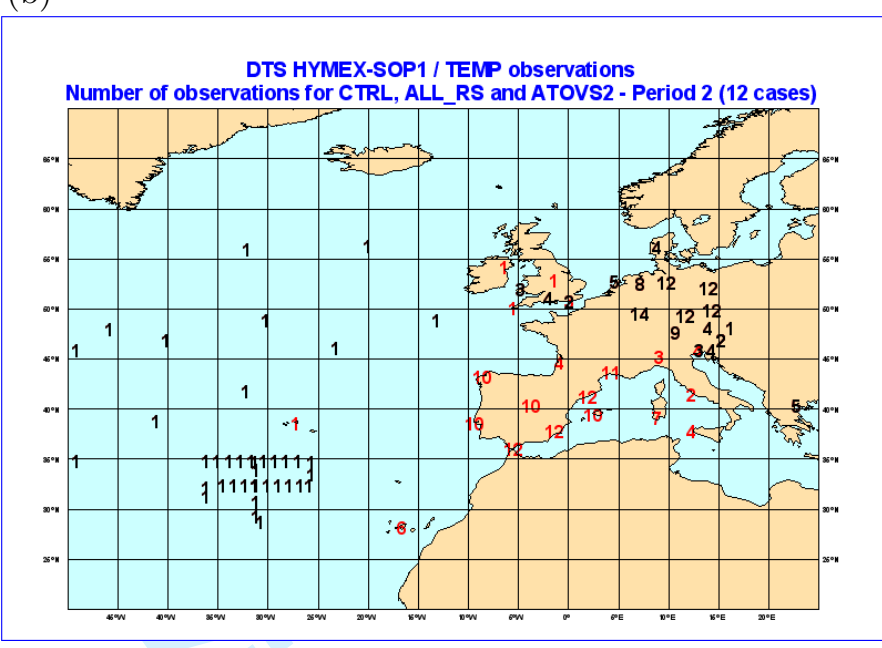

Figure 7: Spatial distribution of upper-air observations assimilated at the targeting times during the first NAO- period: (a) Mean relative difference (in \%) of ATOVS data assimilated between ATOVS2/ATOVS2_B experiments and the baseline, and (b) number of operational (black) and DTS (red) radiosondes. 
(a)

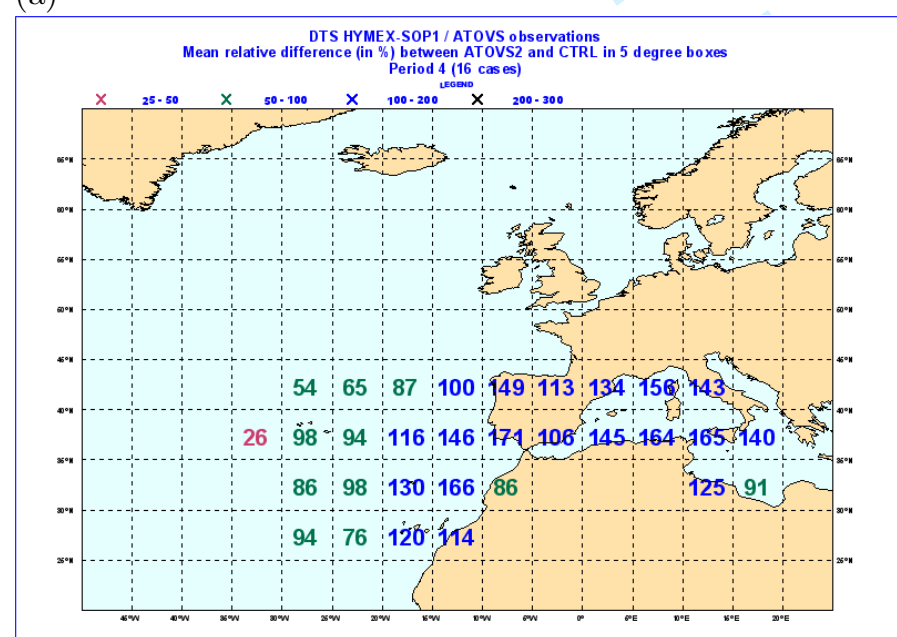

(b)

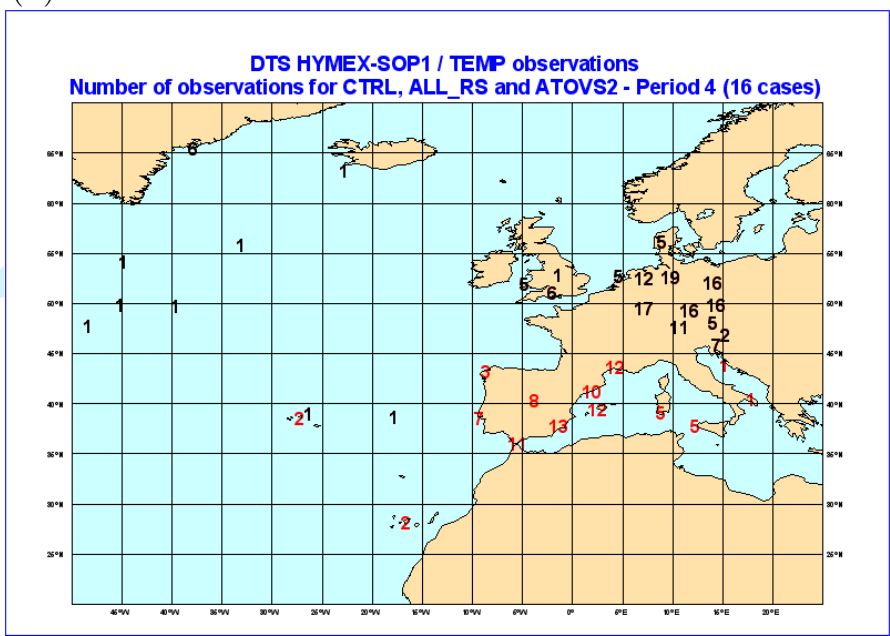

Figure 8. As Figure 7 for the Blocking period. 
(a)

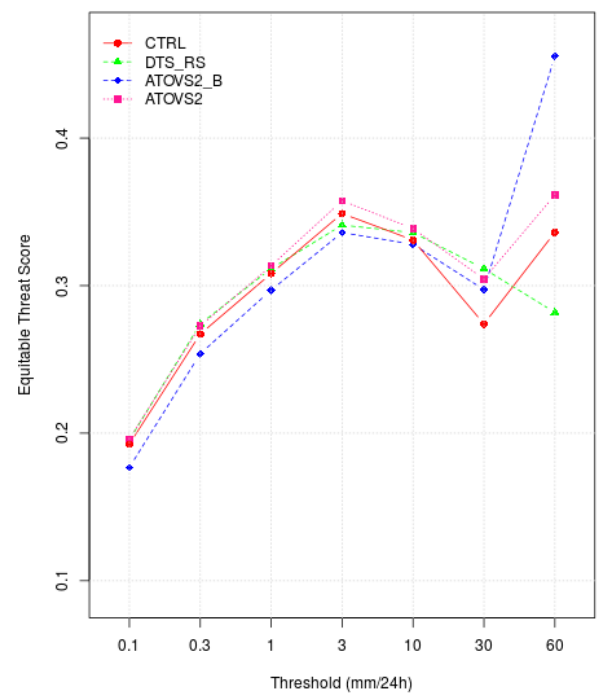

(c)

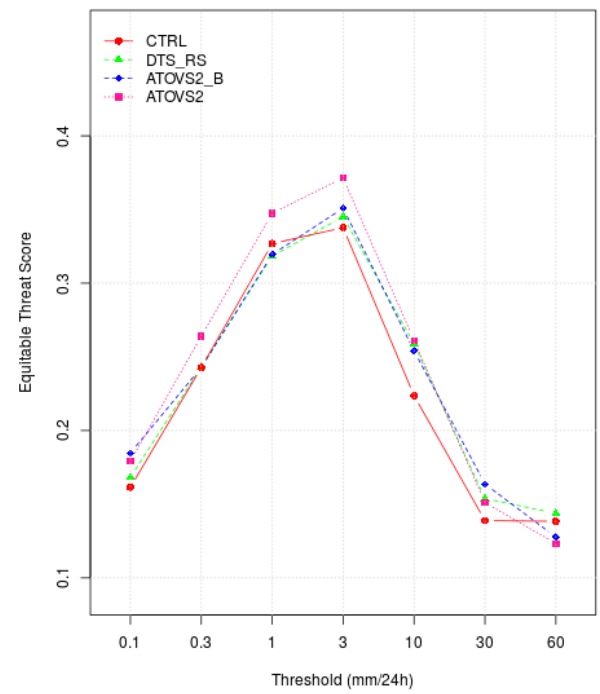

(e)

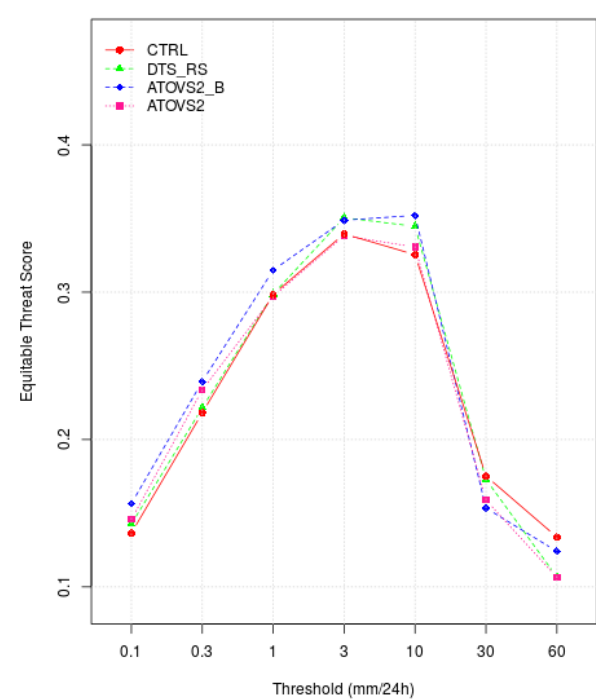

(b)

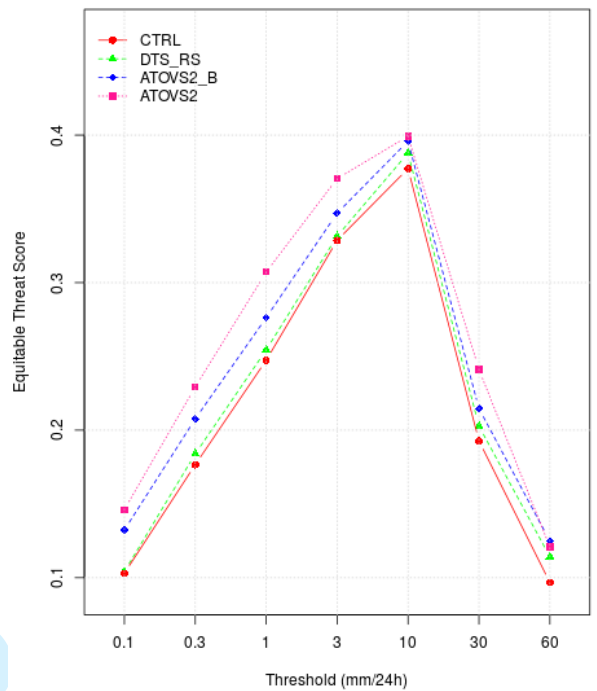

(d)

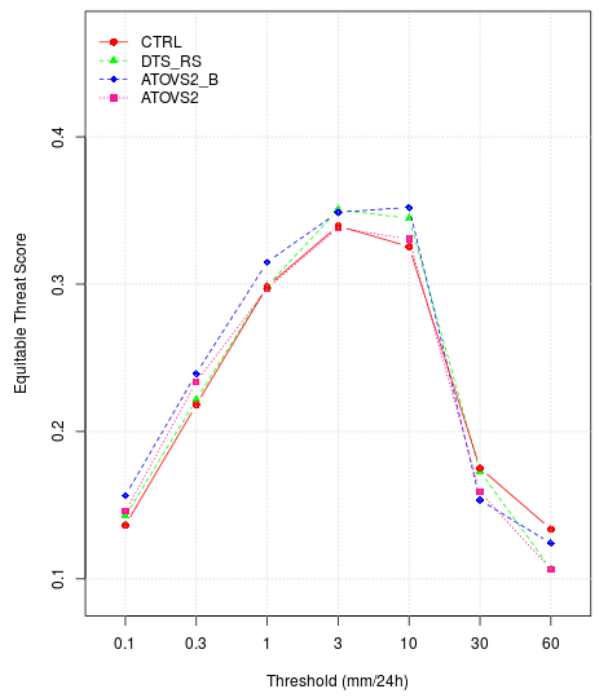

Figure 9: Equitable threat score for 24-h accumulated precipitation for all the cases registered during: Atlantic ridge (a), first NAO- (b), NAO+ (c), Blocking (d) and second NAO- (e). Scores for CTRL (red), DTS_RS (green), ATOVS2_B (blue), and ATOVS2 (violet). 